\title{
The Atmospheric Response to Positive IPV, Positive AMV, and Their Combination in Boreal Winter ${ }^{\mathscr{O}}$
}

\author{
Dillon Elsbury AND Yannick Peings \\ Department of Earth System Science, University of California, Irvine, Irvine, California \\ DAVID SAINT-Martin AND Hervé Douville \\ CNRM-GMGEC, Météo-France, Toulouse, France \\ GUDRUN MAGNUSDOTTIR \\ Department of Earth System Science, University of California, Irvine, Irvine, California
}

(Manuscript received 28 June 2018, in final form 6 February 2019)

\begin{abstract}
The interdecadal Pacific oscillation (hereafter termed IPV, using "variability" in lieu of "oscillation") and the Atlantic multidecadal oscillation (hereafter AMV, similar to IPV) are regulators of global mean temperature, large-scale atmospheric circulation, regional temperature and precipitation, and related extreme events. Despite a growing recognition of their importance, the combined influence of these modes of lowfrequency sea surface temperature (SST) variability remains elusive given the short instrumental record and the difficulty of coupled climate models to simulate them satisfactorily. In this study, idealized simulations with two atmospheric global climate models (AGCMs) are used to show a partial cancellation of the North Pacific atmospheric response to positive IPV (i.e., deeper Aleutian low) by the concurrent positive phase of the AMV. This effect arises from a modulation of the interbasin Walker circulation that weakens deep convection in the western Pacific and the associated Rossby wave train into the northern extratropics. The weaker Aleutian low response is associated with less upward wave activity flux in the North Pacific; however, the associated stratospheric jet weakening is similar to when the +IPV alone forces the vortex, as additional upward wave activity flux over Siberia makes up the difference. While comparable warming of the polar stratosphere is found when the positive AMV is included with the positive IPV, the downward propagation of the stratospheric response is significantly reduced, which has implications for the associated surface temperature extremes. The robust anticorrelation between the positive IPV and positive AMV signals over the North Pacific and their lack of additivity highlight the need to consider the IPV-AMV interplay for anticipating decadal changes in mean climate and extreme events in the Northern Hemisphere.
\end{abstract}

\section{Introduction and motivation}

Decadal to multidecadal internal fluctuations of sea surface temperature (SST) in the Pacific and North Atlantic drive substantial variations in Earth's climate and are potential sources of predictability for regional temperature and/or precipitation at these time scales (Kerr 2000; England et al. 2014; Dong and Dai 2015;

Supplemental information related to this paper is available at the Journals Online website: https://doi.org/10.1175/JCLI-D-180422.s1.

Corresponding author: Dillon Elsbury, delsbury@uci.edu
Cassou et al. 2017). Traditionally the leading mode of interannual to multidecadal SST variability in the Pacific is termed the Pacific decadal oscillation (PDO), the first empirical orthogonal function (EOF) of monthly SST anomalies in the Pacific poleward of $20^{\circ} \mathrm{N}$ (Mantua et al. 1997). However, we focus on the interdecadal Pacific oscillation (hereafter termed IPV, using "variability" in lieu of "oscillation"), the basinwide manifestation of the PDO, extending from $60^{\circ} \mathrm{N}$ to $45^{\circ} \mathrm{S}$ in a tripole pattern of SST anomalies and alternating between warm and cool conditions with a periodicity of 20-30 years (Henley et al. 2015). The IPV is known to be a regulator of global mean surface air temperature and precipitation with farreaching teleconnections, affecting climate variability in 
North America, southern Africa, Australia, and India (Dong and Dai 2015; Joshi and Rai 2015). The extensive network of IPV teleconnections is largely consistent with those forced by El Niño-Southern Oscillation (ENSO), as the IPV is a multidecadal representation of the state of the Pacific SST (Horel and Wallace 1981; Ham et al. 2017; García-Serrano et al. 2017). It also may drive decadal fluctuations in the global temperature that accelerate or decelerate the global warming trend, such as the recent hiatus in atmospheric warming (Meehl et al. 2013; Kosaka and Xie 2013).

In the Atlantic basin, SST alternates between warm and cool conditions with a periodicity of $60-80$ years, although paleoclimatic records show that individual phases have ensued for longer (Kerr 2000; Gray et al. 2004; Trenberth and Shea 2006; Knudsen et al. 2011). This mode of variability, referred to as the Atlantic multidecadal oscillation (hereafter AMV, similar to IPV above) is thought to be mainly driven by internal fluctuations of the ocean-atmosphere system, although it is also influenced by natural and anthropogenic external forcings (greenhouse gases, aerosols, volcanoes, solar radiation) (Knight et al. 2005; Ting et al. 2009; Otterå et al. 2010; Booth et al. 2012; Terray 2012; Knudsen et al. 2014; Tandon and Kushner 2015). The mechanism for $\mathrm{AMV}$, and in particular the role of ocean dynamics, is still controversial (Clement et al. 2015; O'Reilly et al. 2016; Cane et al. 2017). However, numerous modeling studies suggest a role for ocean dynamics, and especially for the Atlantic meridional overturning circulation (AMOC), that is associated with meridional oceanic heat transport and AMV-like SST anomalies in the North Atlantic (e.g., Delworth et al. 1993; Knight et al. 2005; Zhang and Wang 2013; Danabasoglu et al. 2016; Delworth et al. 2017; Kim et al. 2018). The phase shifts in AMV are an important source of decadal predictability of climate. For example, they have been linked with multidecadal fluctuations in tropical cyclone activity (e.g., Vimont and Kossin 2007), Sahel monsoon rainfall (Wang et al. 2012) and temperature/precipitation over North America and Europe (Enfield et al. 2001; Sutton and Hodson 2005). The AMV has also been shown to be associated with long-term trends in the North Atlantic Oscillation (NAO; Hurrell and van Loon 1997), and the AMV has been suggested as a driver of multidecadal variability in North Atlantic weather regimes and associated extreme weather over Europe (Peings and Magnusdottir 2014; Omrani et al. 2014; Peings and Magnusdottir 2016).

Individually, both the AMV and IPV yield some predictive skill for climate on decadal time scales. Yet, their interplay and combined influence on the largescale atmospheric circulation have not received much attention until recently. Constructive and destructive interference of the AMV and IPV modes during the twentieth century has been investigated, for instance in connection with the multidecadal variability of summer monsoon rainfall over the Indian subcontinent (Joshi and Rai 2015). When combined, the IPV and AMV explain more multidecadal variance in precipitation and temperature variability over the United States than when taken individually (Jiang et al. 2013; Steinman et al. 2015). Furthermore, during the early twentieth century, changes in atmospheric circulation associated with the concurrent phase shift of the IPV and AMV from negative to positive coincided with rapid warming of the Arctic (Tokinaga et al. 2017).

With the recent transition of the IPV into its positive phase (Meehl et al. 2016), both the IPV and AMV currently exhibit positive polarity, the AMV having been in its positive phase since the mid-1990s (Trenberth et al. 2017). A decadal prediction initialized in 2013 revealed an IPV transition from negative to positive in 2015 following what is thought to have been sufficient build-up of offequatorial ocean heat content in the tropical western Pacific (Meehl et al. 2016; Henley et al. 2017). Although there is not a single conclusive mechanism for IPV phase shifts (Newman et al. 2016), several studies suggest a role for AMV in altering IPV phase. When the North Atlantic is warmer than average, consistent with positive AMV, an interbasin teleconnection arises via the Walker circulation bridging the Atlantic and the Pacific, leading to a strengthening of the trade winds and cooling via Ekman drift (Kang et al. 2014; England et al. 2014, McGregor et al. 2014; Chafik et al. 2016). Despite the proposed link between + AMV and the IPV phase shift to negative ( 1999), it has yet to be determined if the positive AMV has always been a forcer of IPV phase shifts (McGregor et al. 2014). This study, however, will focus on the concurrent atmospheric response to these modes and not how one mode may affect the other's phase.

Given the current positive polarity of both SST modes, it is imperative to dissect the atmospheric response they elicit. Additionally, with an AMV phase shift predicted to be looming (Frajka-Williams et al. 2017), the atmospheric response to a positive IPV forcing alone must be investigated further. Exploring the combined influence of AMV and IPV is particularly useful to anticipate decadal shifts in jet/storm track variability and associated extreme weather events in the Northern Hemisphere (Peings and Magnusdottir 2016).

The combined influence of IPV and AMV on the polar stratosphere is largely unknown. Both AMV and IPV have been shown to force a stratospheric response in AGCMs that resolve the stratosphere (Omrani et al. 2014; Peings and Magnusdottir 2014; Kren et al. 2016). Notably, perturbations of the Aleutian low influence the 
vertical and meridional propagation of Rossby waves toward the polar stratosphere during boreal winter (Kren et al. 2016; Kang and Tziperman 2017; Yang et al. 2017; $\mathrm{Hu}$ et al. 2017). These planetary waves ascend from the domain of the Aleutian low (Woo et al. 2015), particularly when it is deepened, increasing in amplitude with height (Plumb 2004). The amplification eventually results in wave breaking in the stratosphere when westward momentum is deposited in the area of breaking and the westerly zonal-mean zonal winds are weakened (Baldwin and Dunkerton 1999; Kren et al. 2016). This deceleration disrupts the stratospheric jet and warms the polar atmosphere (Polvani et al. 2017). Poleward and vertical wave activity flux from the midlatitudes, notably the Aleutian low, is key in understanding disruptions to the polar stratospheric jet. Numerous modeling and observational studies have explored the link between ENSO or IPV-like SST forcings and perturbations to the Arctic stratosphere during boreal winter (e.g., García-Herrera et al. 2006; Cagnazzo and Manzini 2009; Kren et al. 2016; Hu et al. 2017; Kang and Tziperman 2017; Yang et al. 2017; Polvani et al. 2017). The teleconnections highlighted in the aforementioned studies are consistent: tropical Pacific SST anomalies initiate an atmospheric Rossby wave train, which strengthens (El Niño) or weakens (La Niña) the deepening of the Aleutian low, affecting planetary wave propagation into the Arctic stratosphere. Yet, a more thorough investigation of the stratospheric response to both IPV and AMV SST variability is critical to increasing our understanding of the large-scale tropospheric response in the boreal winter extratropics.

In this paper, we explore the respective influence of AMV and IPV SST anomalies on the wintertime atmospheric circulation, using a set of idealized sensitivity experiments with two AGCMs. Section 2 describes the models and the experimental protocol. Section 3 presents the main results, with a discussion of the large-scale atmospheric response over the Pacific, the interactions between the IPV and AMV forcings, the response induced in the stratosphere, and the associated changes in temperature extremes over the continents. Finally, section 4 discusses our key results in the context of the observational record by using reanalysis datasets and provides a synopsis of these key findings.

\section{Methods}

Two independent AGCMs are used in this study. The Whole Atmosphere Community Climate Model (WACCM) is a high-top chemistry-climate model that extends to $5.1 \times 10^{-6} \mathrm{hPa}$, to roughly $145 \mathrm{~km}$ (Marsh et al. 2013), with 66 vertical levels. We use its version 4 , which has a horizontal resolution of $1.9^{\circ}$ latitude $\times 2.5^{\circ}$ longitude. We use the Specified Chemistry version (SCWACCM; Smith et al. 2014) and prescribe the observed 28-month quasi-biennial oscillation (QBO). The second model, ARPEGE-Climat, is also a high-top climate model, which has been prepared for CNRM-CM6.1 (Voldoire et al. 2019) to be used in CMIP6 and which has been derived from the atmospheric component of CNRM-CM5 (Voldoire et al. 2013). We use its version 6, with an equivalent $1.4^{\circ}$ latitude $\times 1.4^{\circ}$ longitude horizontal resolution and with 91 vertical levels from the surface to $0.01 \mathrm{hPa}$, approximately $80 \mathrm{~km}$. This model includes a parameterization of nonorographic gravity waves based on the stochastic parameterization described in Lott et al. (2012), which allows the simulation of a spontaneous QBO.

A total of nine simulations have been carried out with each model, which include every combination of IPV and AMV polarity. Given that each mode can exist in a negative, neutral, or positive state, there are nine combinations of SST variability. However, we focus our analysis on four of these experiments: 1) neutral IPV and neutral AMV (control), 2) + IPV and neutral AMV (referred to as +IPV), 3) neutral IPV and + AMV (referred to as +AMV), and 4) +IPV and + AMV (referred to as + AIV). By focusing on this combination of experiments, we will investigate the relative influence of + IPV and + AMV forcing in the midlatitudes, in particular the North Pacific, and how they combine when both forcings are present.

The neutral IPV, neutral AMV experiment is the control. For each model, it consists of a $200-y r$ simulation (after a 1-yr spinup) forced with climatological monthly mean SST/sea ice concentration [1979-2008 average annual cycle from the Hadley Centre Sea Ice and Sea Surface Temperature dataset (HadISST); Rayner et al. 2003]. The external radiative forcings (greenhouse gases, aerosols, solar radiation) are kept constant to present-day values. Each perturbed experiment is run with its corresponding SST anomaly superimposed onto the climatological SST field, with a buffer zone at the edge to avoid steps in the SST spatial distribution.

The prescribed IPV and AMV SST patterns are those designed for the Decadal Climate Prediction Project (DCPP; Boer et al. 2016). To calculate the anomalies associated with each mode, the influence of external drivers of decadal climate variability has been removed from the observed SSTs. This external component includes natural (solar and volcanic) and anthropogenically (greenhouse gases and aerosols) forced SST variations (Boer et al. 2016). To calculate this external component, signal-to-noise maximizing EOF analysis has been applied to the global mean SST derived from a 


\section{Forcing Fields - Sea Surface Temperature $\left({ }^{\circ} \mathrm{C}\right)$}
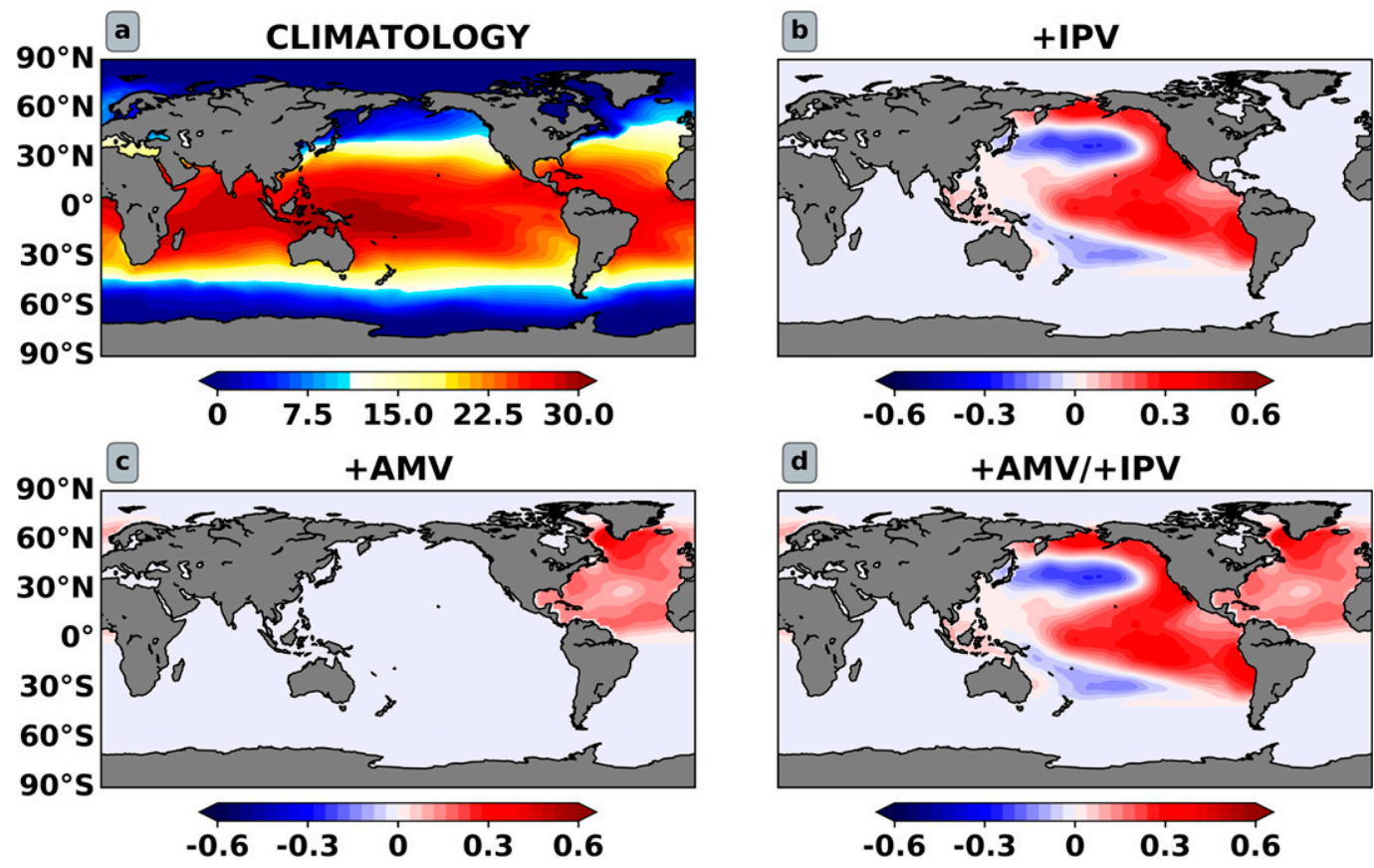

FIG. 1. (a) The climatological SST pattern, neutral IPV, and neutral AMV (control). IPV and AMV SST forcing fields are shown, which range between \pm 1 standard deviation over 1900-2013. (b) + IPV and neutral AMV (+IPV); (c) neutral IPV and + AMV (+AMV); (d) + IPV and + AMV (+AIV). SSTs range between $-0.6^{\circ}$ and $0.6^{\circ} \mathrm{C}$.

CMIP5 multimodel ensemble run utilizing the representative concentration pathway 8.5 (RCP8.5) scenario extending from 1870 to 2013 (Ting et al. 2009; Boer et al. 2016). The IPV and AMV indices are the filtered, latitude weighted differences between the annual mean raw observed SST from the Extended Reconstructed Sea Surface Temperature version 4 (ERSST.v4) dataset and the external component described above in the Pacific $\left(60^{\circ} \mathrm{N}-40^{\circ} \mathrm{S}\right)$ and Atlantic $\left(60^{\circ} \mathrm{N}-0^{\circ} \mathrm{S}\right)$ (Ting et al. 2009; Huang et al. 2015; Boer et al. 2016). ERSST.v4 global SSTs from 1900 to 2013 are regressed onto the IPV and AMV temporal indices to create the spatial patterns associated with each mode. The anomalies that we impose in our experiments correspond to +1 and -1 standard deviation of the AMV and IPV indices (Fig. 1). The response to IPV and AMV SST anomalies is derived by subtracting the 200 -yr mean of the control run from the 200-yr mean of each perturbation run. A twosided Student's $t$ test is used to assess the statistical significance of each response.

\section{Results}

The focus is first on the large-scale boreal winter atmospheric response simulated by WACCM. The tropospheric and stratospheric pathways of this response will be analyzed thoroughly. A brief comparison with the results of the ARPEGE-Climat AGCM will follow in order to highlight the robustness of the atmospheric response over the North Pacific, but also the model-dependent mechanisms behind this common response.

\section{a. The large-scale midtropospheric response}

Extended boreal winter [December-March (DJFM)] 500-hPa streamfunction anomalies simulated by WACCM are shown in Fig. 2. Positive IPV (+IPV) forcing results in a positive Pacific-North American (PNA) pattern (Fig. 2a). Conversely, negative IPV forcing results in a negative PNA pattern (not shown). That is, via a Rossby wave train propagating out of the subtropical Pacific, there are alternating positive (anticyclonic) and negative (cyclonic) nodes of streamfunction anomalies spaced about $6000 \mathrm{~km}$ apart that are directed poleward before curving eastward across North America, and finally equatorward over the tropical Atlantic (Horel and Wallace 1981). Consistent with this response is a deepening of the Aleutian low, which has implications for the surrounding landmasses; specifically, warmer temperatures over Alaska, northwestern Canada, and the northwestern part of the United States (Wallace and Gutzler 1981; Kren et al. 2016). 
WACCM DJFM 500 hPa Streamfunction Anomalies $\left(10^{6} \mathrm{~m}^{2} \mathrm{~s}^{-1}\right)$

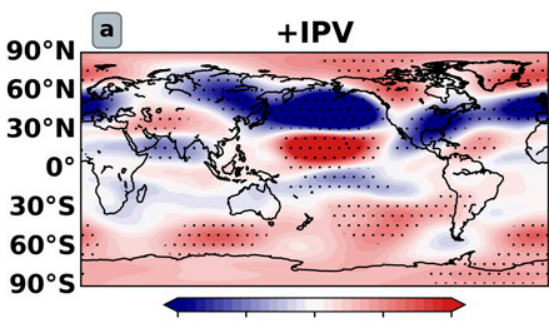

$\begin{array}{llllll}-1.0 & -0.5 & 0 & 0.5 & 1.0\end{array}$

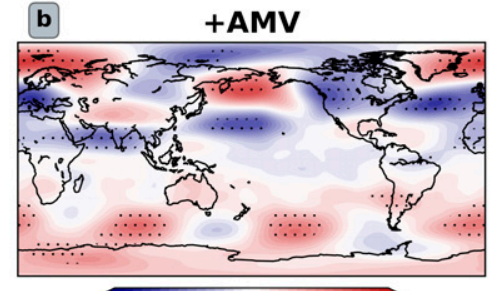

$\begin{array}{llllll}-1.0 & -0.5 & 0 & 0.5 & 1.0\end{array}$
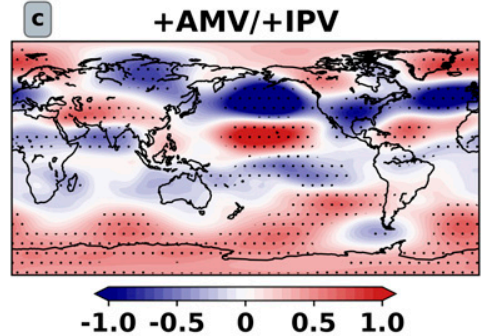

WACCM DJFM Sea Level Pressure Anomalies (hPa)

d

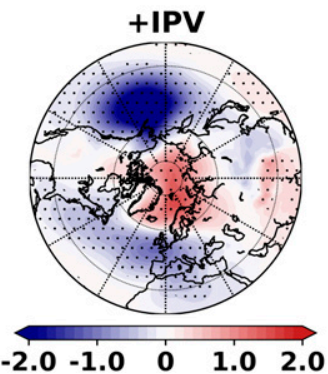

e

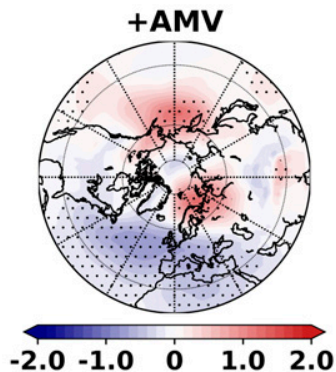

f

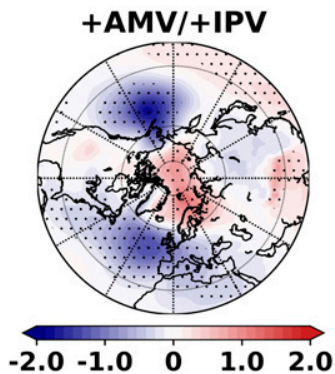

FIG. 2. Extended winter 500-hPa streamfunction anomalies for the (a) +IPV, (b) + AMV, and (c) + AIV perturbations. Focusing on the Northern Hemisphere, positive (anticyclonic) anomalies are shown in red and negative (cyclonic) anomalies are shown in blue. (d)-(f) Sea level pressure anomalies for the three perturbation experiments. Hatching indicates statistical significance at or above $95 \%$.

Deepening of the Aleutian low is also observed at sea level, which is expected as the extratropical Rossby wave nodes are equivalent barotropic (Fig. 2d).

The response of 500-hPa streamfunction and sea level pressure to positive AMV (+AMV) is shown in Figs. 2b and 2e. In the North Atlantic, the signal resembles the negative NAO [consistent with WACCM experiments from Peings and Magnusdottir (2016)]. In the North Pacific, the response opposes the effect of +IPV. The + AMV drives the formation of a cyclonic anomaly in the tropical-subtropical Pacific (Fig. 2b, centered near $170^{\circ} \mathrm{E}$ ) and an anticyclonic anomaly in the extratropical Pacific (Fig. 2b, centered near $170^{\circ} \mathrm{E}$ ). These two anomalies are opposite in sign to the anomalies induced by the +IPV forcing (Fig. 2a). When both are combined (+AIV; Fig. 2c), the signal is broadly similar to + IPV (Fig. 2a), but with weaker anomalies over the North Pacific due to the cancellation effect of + AMV. This is quantified in Fig. 3, which shows the spatial correlation of the +IPV (blue) and the + AMV 500-hPa streamfunction responses (red) with the + AIV 500-hPa streamfunction response over the North Atlantic, the North Pacific, and the Northern Hemisphere (NH), from the equator to $65^{\circ} \mathrm{N}$. Also shown is the root-meansquare error (RMSE) between the individual forcing experiments and the +AIV. The NH response is dominated by +IPV, as shown by the strong correlation and low RMSE between + IPV and + AIV (Fig. 3c). Over the North Atlantic, both the +IPV and + AMV are highly correlated with + AIV, suggesting mutual influence in the response (Fig. 3a). However, the +AMV and + IPV responses are anticorrelated in the North Pacific (Fig. 3b), since the +AMV dampens the first two nodes of the PNA Rossby wave train (Fig. 2b). Notably, the +AMV weakens the deepening of the Aleutian low. This is a central point to this paper. To investigate the relationship between the +AMV forcing and the response it elicits in the North Pacific, we shift our focus to the upper troposphere.

\section{b. Atmospheric response to $+A M V$ forcing}

The WACCM 200-hPa velocity potential and divergent wind anomalies associated with each perturbation experiment are shown in Figs. 4b-d. The +IPV broadly induces a response that resembles that to El Niño, with decreased (increased) large-scale divergence in the tropical western (eastern) Pacific (Fig. 4b). However, the pattern of the anomalies is less organized than a typical El Niño signal (García-Serrano et al. 2017), with alternation of increased divergence and convergence north of the equator.

Following anomalous 200-hPa divergence in the tropical Atlantic (Fig. 4c), interbasin communication occurs via the upper branch of the Walker circulation, terminating in convergence at $200 \mathrm{hPa}$ over the Maritime Continent with subsidence below (Fig. S1c in the online 
WACCM Spatial Correlation and RMSE of +AMV/+IPV with + AIV

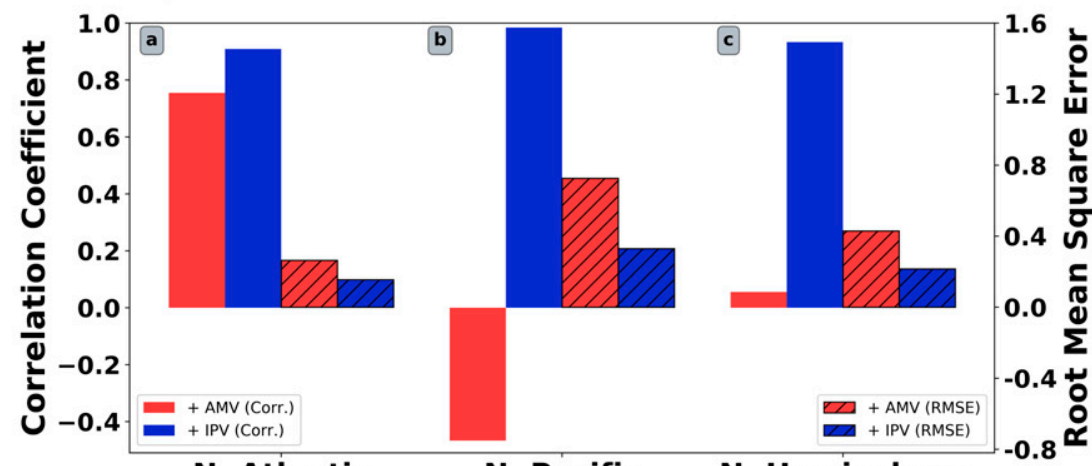

N. Atlantic

N. Pacific

N. Hemisphere

FIG. 3. Spatial correlations of the +IPV (blue) and the + AMV (red) 500-hPa streamfunction anomalies with the + AIV 500-hPa streamfunction anomalies. Correlations are calculated in the (a) North Atlantic $\left(0^{\circ}-65^{\circ} \mathrm{N}, 70^{\circ}-10^{\circ} \mathrm{W}\right)$ and (b) North Pacific $\left(0^{\circ}-65^{\circ} \mathrm{N}, 140^{\circ} \mathrm{E}-120^{\circ} \mathrm{W}\right)$, and (c) across the Northern Hemisphere $\left(0^{\circ}-65^{\circ} \mathrm{N}, 180^{\circ}-180^{\circ}\right)$. Root-mean-square errors (hatched bars) are calculated using the same methodology.

supplemental material; wind vectors not shown). This effect is conserved during the + AIV forcing experiment (Fig. 4d), when the +AMV appears to reinforce the convergence over the Maritime Continent seen for +IPV (Fig. 4b). However, this anomalous convergence is not confined to the deep tropics in this region. It is observed at $200 \mathrm{hPa}$ over the Philippine Sea, the South China Sea, and the East China Sea (Fig. 4d), Rossby wave source regions that respond to the locally intense horizontal vorticity gradient associated with the edge of the jet stream (Sardeshmukh and Hoskins 1988; Watson et al. 2016; Scaife et al. 2017). We assert that + AMV forces

\section{WACCM DJFM $200 \mathrm{hPa}$ Velocity Potential Anomalies $\left(10^{5} \mathrm{~m}^{2} \mathrm{~s}^{-1}\right)$}
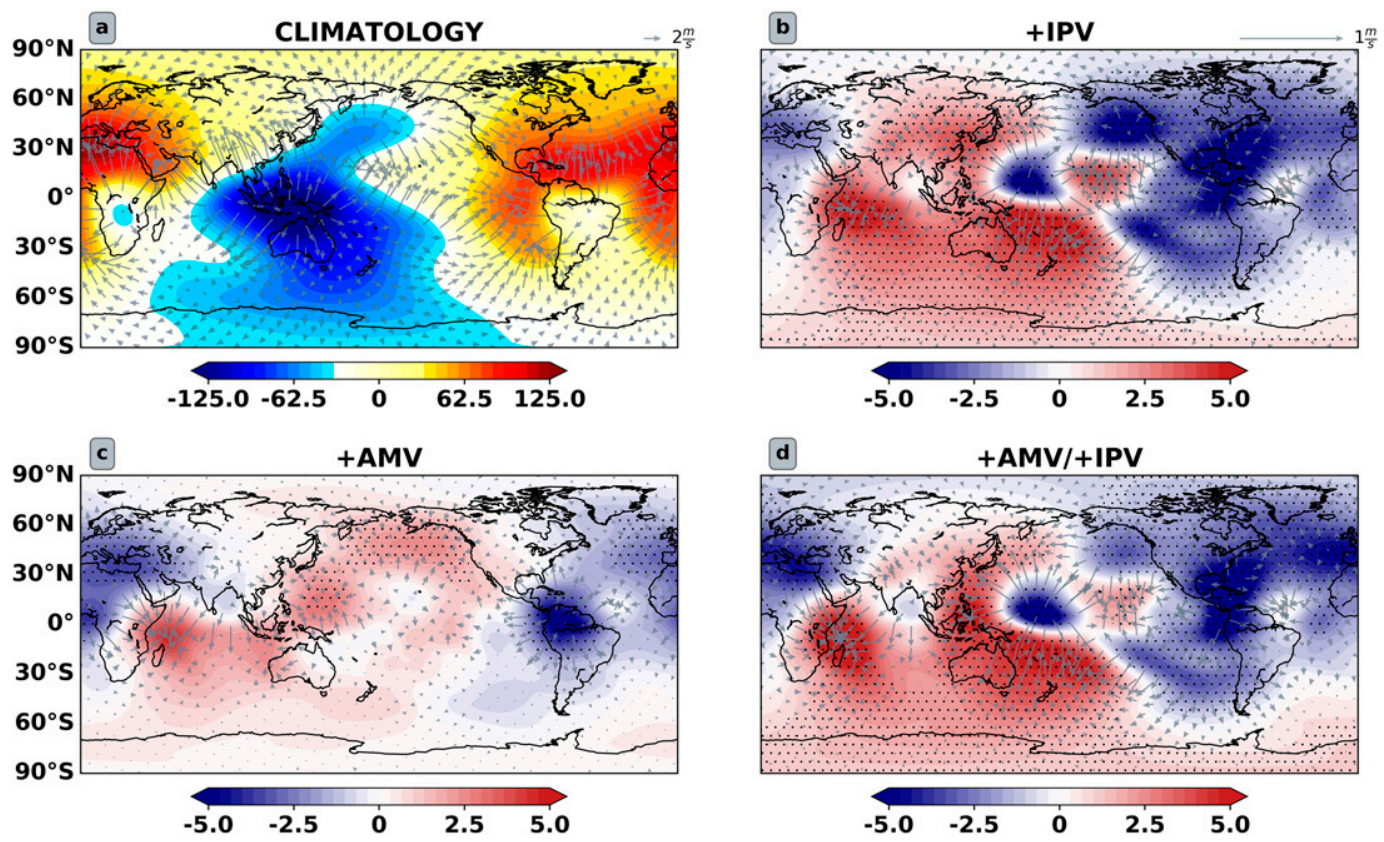

FIG. 4. Extended winter 200-hPa velocity potential anomalies for the (b) +IPV, (c) + AMV, and (d) + AIV perturbations; the (a) climatological pattern is shown with a different color scale. Positive (red) anomalies are areas of convergence and negative (blue) anomalies are areas of divergence. Divergent wind vectors are shown in gray. Hatching with black dots indicates statistical significance at or above $95 \%$. 


\section{WACCM DJFM Z200x Anomalies (m)}

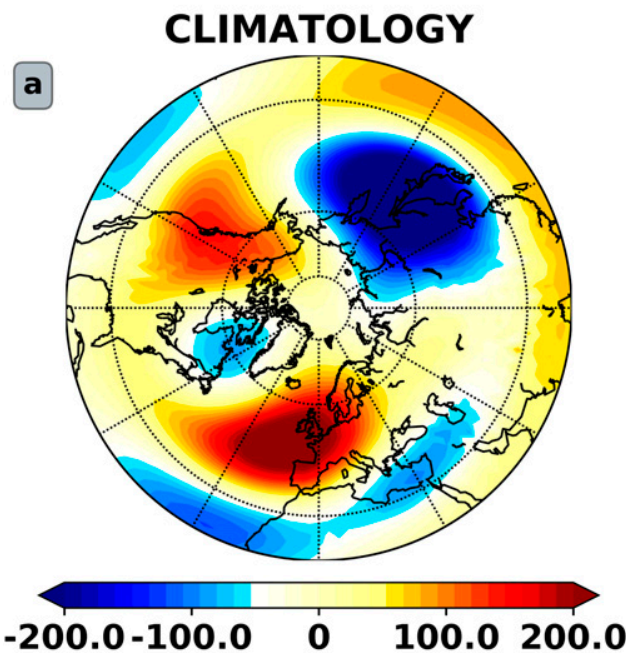

b
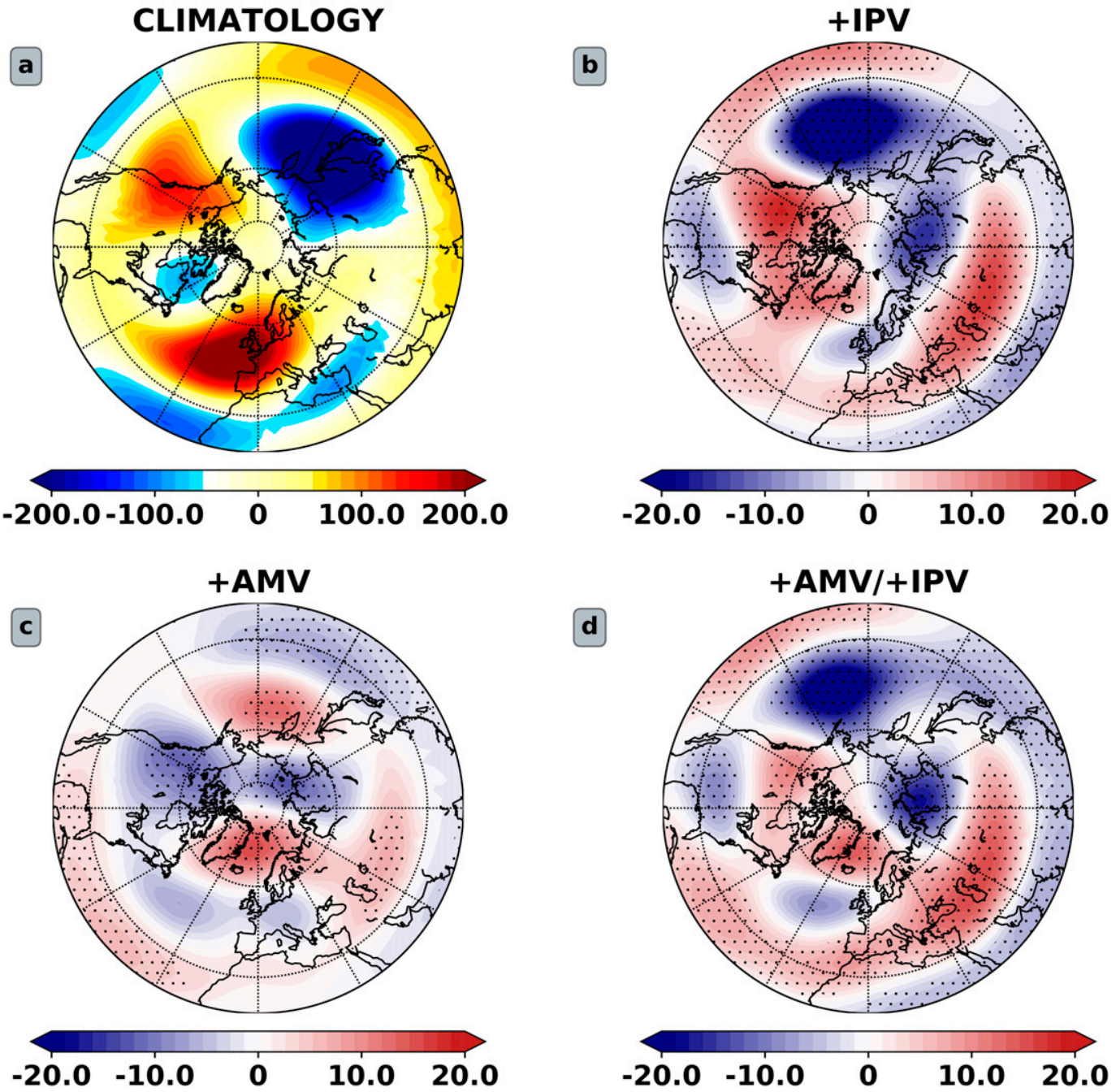

FIG. 5. Extended winter 200-hPa Z200x anomalies (the "x" denotes the removal of the zonal mean from the geopotential field) for the (b) +IPV, (c) + AMV, and (d) + AIV perturbations; the (a) climatological component is shown using a different color scale. Hatching with black dots indicates statistical significance at or above $95 \%$.

upper-level convergence in the tropical western Pacific, reducing the Rossby wave generation that deepens the Aleutian low.

The 200-hPa stationary waves over the Pacific support this assertion. Figure 5a shows the climatological field of 200-hPa geopotential with the zonal mean removed. The + AMV forcing generates a wave train (Fig. 5c) that propagates out of the tropical west Pacific into the North Pacific where it increases the local height field and partially cancels out the upper-level trough driven by +IPV (Fig. 5b). This effect is apparent in the +AIV case (Fig. 5d) as the Aleutian low is smaller in extent compared to the +IPV case (Fig. 5b)
Previous studies have shown this modulation of the North Pacific atmosphere by the AMV. Sun et al. (2017) argue that the connection between the + AMV and the North Pacific is twofold: 1) upper tropospheric divergence over the North Atlantic is compensated for by upper tropospheric convergence in the North Pacific, subsequent subsidence, and formation of high pressure and 2) upper-tropospheric convergence in the tropical central-eastern Pacific induced by the + AMV can initiate a Rossby wave train propagating into the extratropics, thereby enhancing the first effect. Similarly, Davini et al. (2015) argue that anomalies associated with + AMV (specifically in the tropical Atlantic) 
excite a Rossby wave train over the Pacific that weakens the Aleutian low in response to a poleward displacement of the intertropical convergence zone (ITCZ). This decadal teleconnection bridging the tropical atmospheres of each basin also operates at the interannual time scale. Perturbations to the Walker circulation induced by positive tropical Atlantic SST anomalies induce upper tropospheric convergence and surface wind changes over the Pacific within one season of the initial forcing (Simpkins et al. 2016). Similarly, perturbations to the Walker circulation induced by ENSO SST lead to warming of tropical North Atlantic SST with just a one season lag (Giannini et al. 2001; Wang 2004; GarcíaSerrano et al. 2017).

\section{c. Link between the midlatitudes and Arctic atmosphere}

To quantify the change in meridional and vertical wave propagation out of the midlatitudes, we calculate daily December-January (DJ) and February-March (FM) Eliassen-Palm (EP) flux anomalies. Pressure coordinates are scaled according to the methodology outlined in Edmon et al. (1980). The EP flux is then divided by the square root of 1000 divided by pressure (Taguchi and Hartmann 2006). Figure 6 includes EP flux (gray arrows with statistically significant arrows in black), divergence of the EP flux (shaded), and zonal wind anomalies (contoured in black) for the three perturbation experiments and for a fourth case where + IPV anomalies are subtracted from + AIV anomalies to highlight how the +AMV modulates the +IPV response.

In response to + IPV forcing, positive EP flux anomalies (driven mainly by the eddy heat flux), consistent with increased planetary wave activity, originate from the troposphere at $45^{\circ} \mathrm{N}$, approximately the location of the Aleutian low. These eddies then propagate toward the Arctic stratosphere (Figs. 6a,b). The negative EP flux divergence between 100 and $10 \mathrm{hPa}$, which results from some combination of effects from wave breaking and diabatic heating, is indicative of wave dissipation and a deceleration of the zonal-mean zonal winds, resulting in a weaker stratospheric jet (Andrews et al. 1987; Kren et al. 2016; Hu et al. 2017; Polvani et al. 2017). Note that the EP flux convergence shifts downward in the stratosphere between early and late winter (cf. Figs. 6a,b). This is concomitant with the extension of easterly zonal wind anomalies into the upper troposphere during late winter, whereas during early winter these anomalies are confined to the stratosphere. These downward propagating zonal wind anomalies are consistent with a negative northern annular mode (NAM).
The + AMV does not perturb the stratospheric winds during early winter (Fig. 6c). However, during late winter, + AMV forcing induces a weak attenuation of the stratospheric jet (Fig. 6d), in line with previous studies (Omrani et al. 2014; Peings and Magnusdottir 2016). The response to the combination of +AMV and + IPV is not additive, either in early (Fig. 6e) or in late winter (Fig. 6f). The +AIV EP flux (and its divergence) emanating predominantly from $45^{\circ} \mathrm{N}$ is weaker in magnitude than the corresponding field for the +IPV case (Figs. 6a,b). The bottom two panels (Figs. 6g,h) illustrate this point by showing the difference in response between the +AIV case and the +IPV case. For the most part, including the + AMV (Figs. 6c,d) forcing weakens both the tropospheric and stratospheric EP flux anomalies of +IPV (Figs. 6a,b). This is a key point, but it is worth noting that the attenuation of the stratospheric jet is largely consistent between the +IPV case and the + AIV case, with the slight exception that the +IPV zonal wind anomalies extend farther into the troposphere.

To better identify source regions of wave activity, we calculate the 150-hPa vertical wave activity flux (WAFz), also called the Plumb flux (Plumb 1985), for the entire Northern Hemisphere. The Plumb flux is a generalization of the EP flux, a three-dimensional flux in a conservation relation that, if zonally averaged, reduces to the EP flux (Plumb 1985). Consistent with Plumb (1985), WACCM exhibits maximum vertical wave propagation in the North Pacific/eastern Asia and the North Atlantic/ western Europe regions (Fig. 7a). With +IPV forcing the upward wave activity flux intensifies over the eastern North Pacific and modestly over the North Atlantic and northern Eurasia (Fig. 7b). Conversely, with + AMV forcing there is reduced upward propagation across the entire North Pacific; however, there is an increase over northern Eurasia with a subsidiary increase over the North Atlantic (Fig. 7c). Given the concurrent positive forcing, the + AIV (Fig. 7d) results in increased upward wave propagation across Eurasia and over the eastern North Pacific, although the latter is reduced compared to the +IPV case. Thus, we observe that the +AMV destructively interferes with upward wave propagation in the North Pacific while amplifying upward wave propagation over Eurasia.

The locations in which we observe enhanced upward wave activity flux (Fig. 7d) coincide well with regions of blocking in the upper troposphere. Blocking has garnered attention because it is associated with variability in stratospheric circulations, namely the occurrence of sudden stratospheric warming (SSW) events (McIntyre 1982; Martius et al. 2009; Nishii et al. 2010; Woo et al. 2015; Kren et al. 2016). In the North Pacific, 


\section{WACCM Eliassen-Palm Flux}
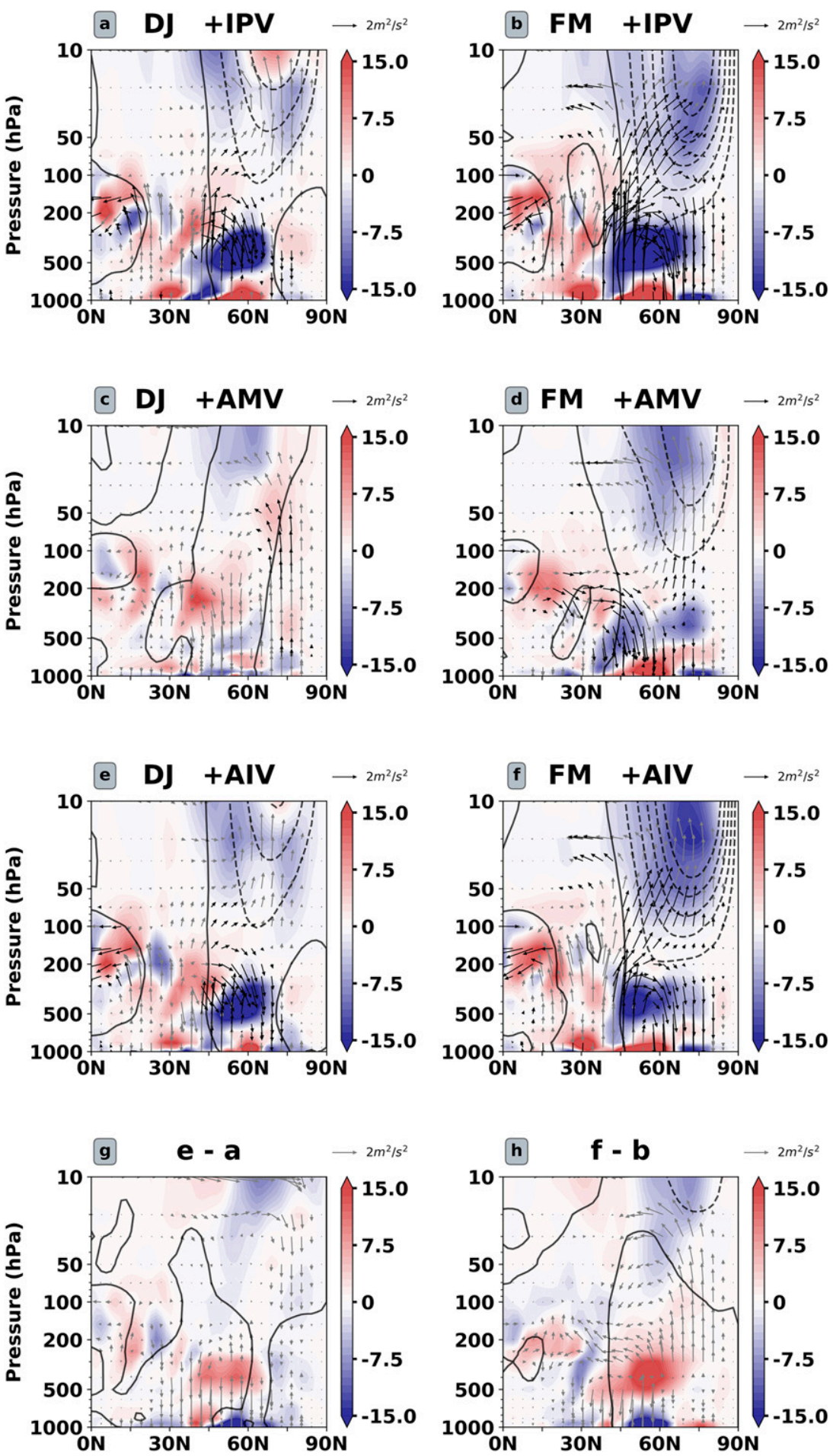

FIG. 6. Early (DJ) and late (FM) winter Eliassen-Palm (EP) flux meridional cross sections for (a), (b) +IPV, (c), (d) + AMV, and (e), (f) + AIV perturbations; (g), (h) the +IPV case subtracted from + AIV. EP flux anomalies (gray arrows; black when the vertical component is statistically significant), EP flux divergence (shading), and zonal wind (contoured in black) anomalies are shown. The meridional domain is from the equator to $90^{\circ} \mathrm{N}$. The zonal wind contour range is from -5 to $5 \mathrm{~m} \mathrm{~s}^{-1}$ (interval of 1). 


\section{WACCM DJFM $150 \mathrm{hPa}$ WAFz Anomalies $\left(10^{2} \mathrm{~m}^{2} \mathrm{~s}^{-2}\right)$}

\section{CLIMATOLOGY}

a

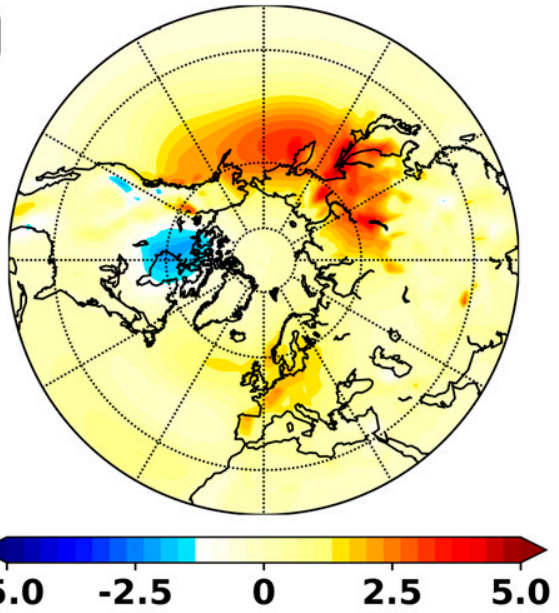

C
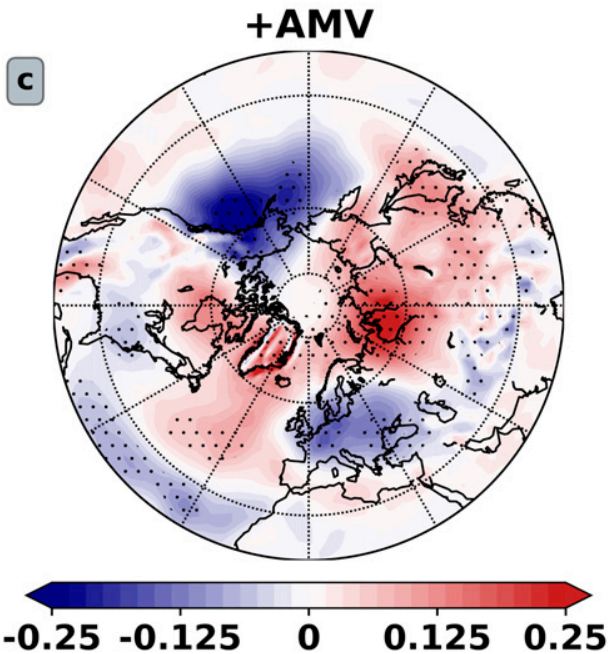

b
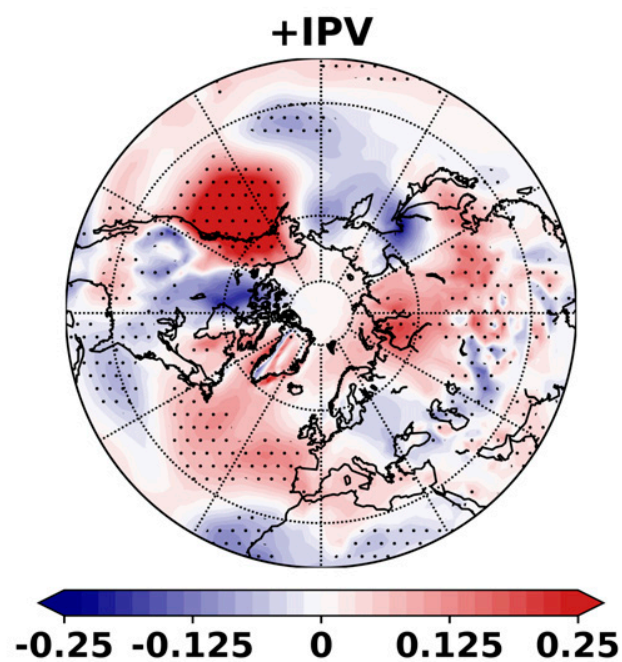

d

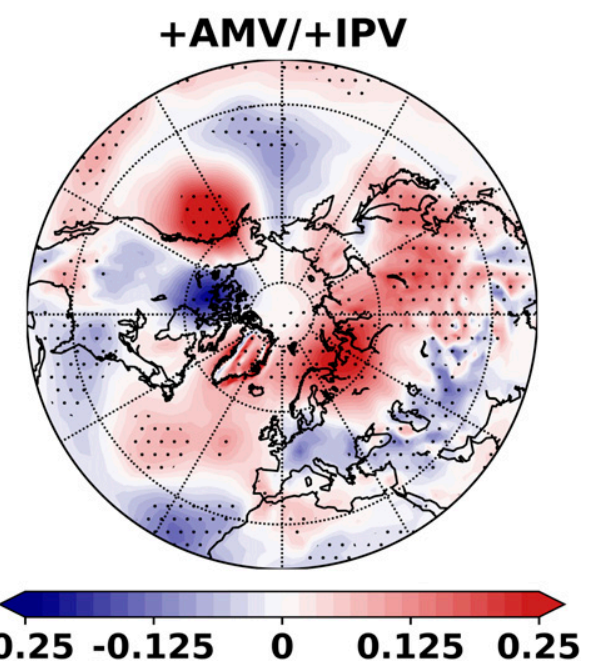

FIG. 7. Extended winter $150-\mathrm{hPa}$ vertical Plumb flux anomalies for (a) the control as well as the (b) +IPV, (c) + AMV and (d) + AIV perturbations. Positive anomalies are shown in red and negative anomalies in blue. Hatching with black dots indicates statistical significance at or above $95 \%$.

superposition of a trough (ridge) on the climatological mean trough in the region increases (decreases) upward propagation of planetary waves, leading to a warming (cooling) of the polar stratosphere (Nishii et al. 2010; Woo et al. 2015). Phase coherence between the topographically forced climatological stationary wave and a forced mode is a prerequisite condition for tropospheric planetary waves to force stratospheric circulation changes (Fletcher and Kushner 2011). This coherence occurs when the phase speed of the response wave and the climatological stationary wave are similar enough for the waves to nearly be in resonance (Andrews et al. 1987). Increases in the amplitude of the climatological stationary wave reduce the phase speed of the response wave, moving both waves closer toward resonance with each other, leading to further amplification of the stationary wave, a positive feedback (Plumb 1981; McIntyre 1982; Andrews et al. 1987). This wave amplification allows the stationary wave to force mean flow changes in the stratosphere. The deepening of the Aleutian low in our + IPV and + AIV (Figs. 2a,c) provide the phase coherence necessary to jumpstart this phenomenon. To quantify this coherence, we create longitude-pressure cross sections of DJFM wave 1 and wave 2 at $60^{\circ} \mathrm{N}$ (not shown) and calculate pressure-weighted pattern correlations between the climatological wave and the response 
TABLE 1. Pressure weighted pattern correlations between the climatological wave pattern at $60^{\circ} \mathrm{N}$ and the response wave forced by the experiments over the North Pacific domain $\left(90^{\circ} \mathrm{E}-90^{\circ} \mathrm{W}\right)$.

\begin{tabular}{lrc}
\hline \hline Forcing field & Wave 1 & Wave 2 \\
\hline+ IPV & 0.69 & 0.69 \\
+ AMV & -0.07 & 0.39 \\
+ AIV & 0.55 & 0.33 \\
\hline
\end{tabular}

wave in the North Pacific, which are presented in Table 1. When compared to the +IPV correlations, + AIV forcing leads to reduced phase coherence of wave 1 and wave 2 with the climatological wave pattern in the North Pacific. This is attributed to the destructive interference of the $+\mathrm{AMV}$, which results in less stratosphere-troposphere coupling over this basin.

As an additional metric of upward planetary wave propagation, the number of SSWs for each experiment is calculated. We use the algorithm of Charlton and Polvani (2007) to identify SSWs: for days between 1 November and 31 March, the central date of a warming is the first day in which the zonal-mean zonal winds at $60^{\circ} \mathrm{N}$ and $10 \mathrm{hPa}$ become easterly. Following identification of the central date, 20 consecutive days of westerly winds must exist before the next central date can be defined (CharltonPerez and Polvani 2011). The control simulation yields 134 SSWs in 200 years, or 0.67 events per extended winter season. This frequency is consistent with previous studies: 0.67 events per season (Charlton and Polvani 2007), 0.63 events per season (Butler et al. 2017), 0.59 events per season (Polvani et al. 2017), and 0.60 events per season (White et al. 2018). The number of SSWs for each of the perturbation experiments is listed in Table 2.

Despite destructive interference with the Aleutian low, + AMV forcing increases the frequency of SSWs by $\sim 14 \%$. This is likely due to enhanced vertical wave activity flux over Eurasia (Fig. 7c). SSW frequency increases $\sim 31 \%$ due to +IPV forcing. The stratospheric response to the +IPV and + AMV is not additive as the + AIV forcing results in a very modest increase in SSWs relative to + IPV. Therefore, although the + AMV dampens the response to the +IPV in the troposphere by weakening the Aleutian low, the +AMV does not dramatically perturb the response to + IPV in the stratosphere. Furthermore, recall that the attenuation of the stratospheric jet is similar in magnitude (slightly different in vertical extent) between the + IPV and + AIV (cf. Figs. 6a,b and Figs. 6e,f).

\section{d. Polar atmospheric response to planetary wave forcing and associated surface extreme temperatures}

To characterize the response of the polar atmosphere to the forcings, we calculate daily geopotential height
TABLE 2. Number and frequency of stratospheric sudden warmings in events per extended winter season. Both number of events and frequency are calculated using daily data (NovemberMarch) over the entire 200-yr period.

\begin{tabular}{lcc}
\hline \hline Forcing field & No. of SSWs & Events per season \\
\hline Control & 134 & 0.67 \\
+ IPV & 176 & 0.88 \\
+ AMV & 153 & 0.77 \\
+ AIV & 179 & 0.90 \\
\hline
\end{tabular}

anomalies averaged over the polar cap (north of $65^{\circ} \mathrm{N}$ ), from 1000 to $10 \mathrm{hPa}$ (Fig. 8). Positive height anomalies manifest throughout the extended winter season due to the +IPV (Fig. 8a). This is expected as the aforementioned upward propagating planetary waves decelerate the stratospheric jet (Figs. 6a,b), inducing a residual circulation (poleward and sinking motion), that is accompanied by adiabatic temperature increase below the forcing region (Dunkerton et al. 1981; Limpasuvan et al. 2004). The warming associated with these stratospheric perturbations consistently propagates downward $(\sim 400 \mathrm{hPa})$ throughout the extended winter season. However, particularly in late winter (February and March), the stratospheric anomalies propagate downward into the troposphere and project onto the negative phase of the NAM (see the Z500 response in Fig. S2b).

Compared to the +IPV case, the Arctic atmospheric response to + AMV forcing (Fig. 8b) is modest with comparatively weak positive anomalies observed in midDecember and March. The early winter warming that begins $\sim 8$ December, seen at $10 \mathrm{hPa}$, propagates downward into the troposphere terminating late in December. This result is consistent with Christiansen (2001), who finds that a minimum time scale for downward propagation of the zonalmean zonal winds associated with the NAM is $\sim 15$ days and that mean temperature anomalies descend slightly slower. During late winter, the height anomalies are slightly stronger in the stratosphere, and propagate farther into the troposphere (as was the case with the +IPV as well).

The + AIV geopotential height anomalies (Fig. 8c) resemble the +IPV-induced signal (in line with the response in SSWs frequency; Table 2), with slightly reinforced anomalies in the stratosphere in late winter, however with more (less) downward propagation in early (late) winter. As illustrated in Fig. 8d (sum of Figs. 8a and 8b) and Fig. 8e (difference between Figs. 8c and $8 \mathrm{~d}$ ), the response to + AMV and + IPV by themselves are not additive, since most of the response in the +AIV simulation is less than the sum of the responses to each of + AMV and +IPV. In particular, a noteworthy difference is the smaller propagation of the 


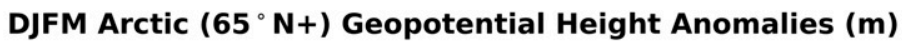
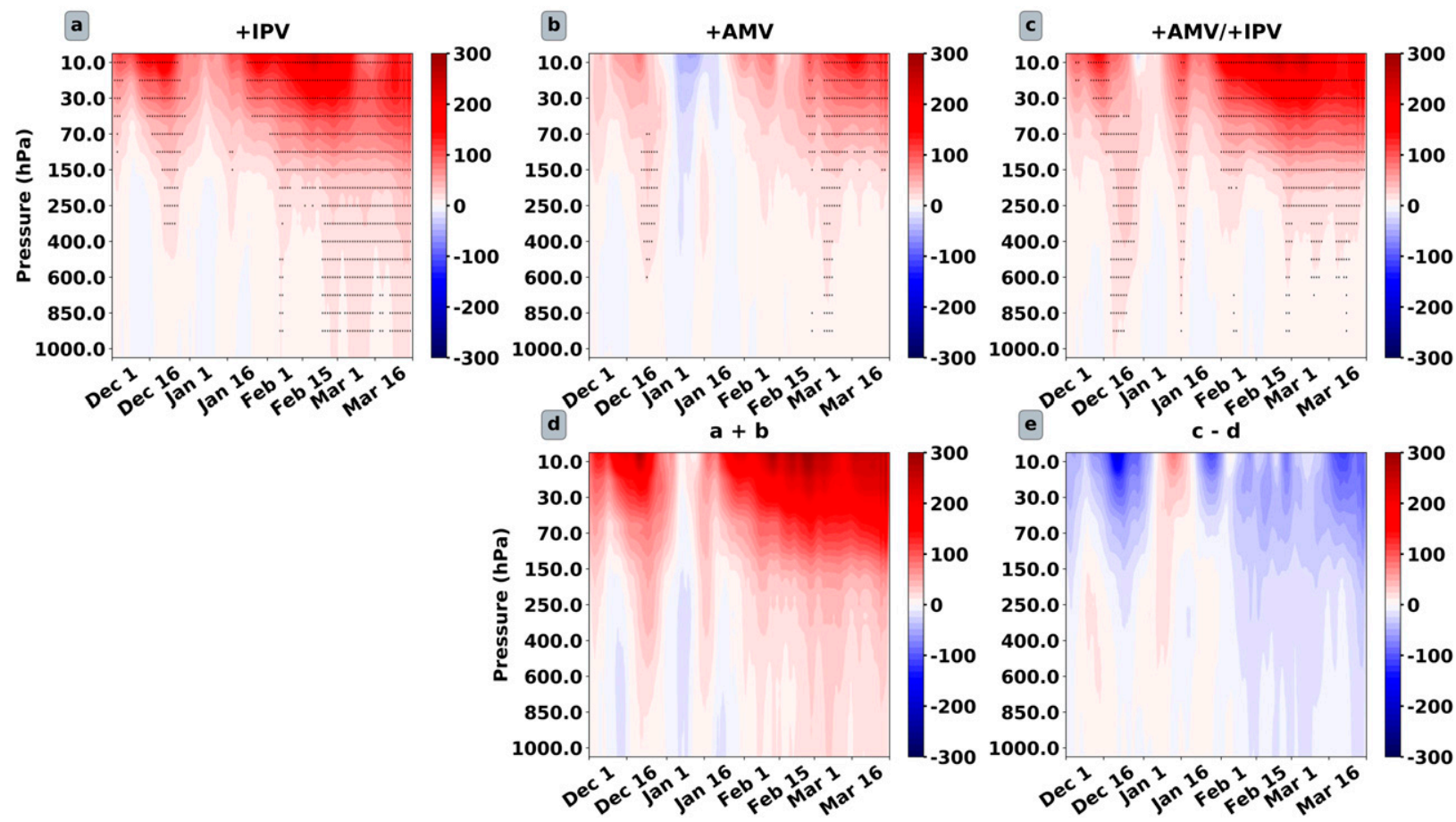

FIG. 8. Extended winter daily geopotential height anomalies averaged over the polar cap north of $65^{\circ} \mathrm{N}$. These cross sections exhibit time (days) on the $x$ axis and pressure levels on the $y$ axis. Shown are the anomalies for the (a) +IPV, (b) + AMV, and (c) + AIV perturbations. Hatching denotes anomalies statistically significant at or above $95 \%$. Two additional composites are calculated: (d) the sum of + IPV and + AMV and (e) the difference between the + AIV anomalies and the aforementioned linear sum in (d).

signal into the troposphere in late winter (Fig. 8e), which is consistent with smaller negative NAM anomalies at $500 \mathrm{hPa}$ in the + AIV simulation compared to + IPV (Fig. S2). Recall that the downward propagation of the easterly zonal wind anomalies during FM terminates at the base of the stratosphere for + AIV (Fig. 6f). We find that this downward propagation of zonal-mean zonal wind anomalies for + AIV is inhibited in the Pacific basin at $300 \mathrm{hPa}$ and in the Atlantic basin at $300 \mathrm{hPa}$ (not shown). This leads us to hypothesize that some combination of baroclinic and quasi-stationary eddies interact with the mean flow in the midlatitude jet to oppose the continued propagation of the easterly zonal-mean zonal wind anomalies downward (Chen and Robinson 1992; Lorenz and Hartmann 2003; Lubis et al. 2016). The exact dynamical explanation likely requires targeted study and is beyond the scope of this paper. Note that with $+\mathrm{IPV}$, the zonal-mean zonal wind anomalies $\left(-1 \mathrm{~m} \mathrm{~s}^{-1}\right)$ propagate downward to $500 \mathrm{hPa}$ (not shown). Thus, when the +AMV is combined with the +IPV, the downward propagation of the NAM is inhibited in the Pacific. This prevents reinforcement of the trough in the North Pacific, potentially a second mechanism by which the + AMV attenuates the Aleutian low.
Given the impacts of SSWs and subsequent downward propagation of NAM anomalies at the surface (Baldwin and Dunkerton 2001), these results have implications for the frequency of extreme weather events at the surface. Figure 9 shows the changes in the frequency of DJ and FM cold extremes with + IPV and + AIV forcing. The Expert Team on Climate Change Detection Indices (ETCCDI) defines cold extremes as the percentage of days below the 10th percentile temperature for a specific location (Karl et al. 1999). The + IPV forcing decreases the frequency of cold extremes over the North American west coast, northern Africa, and Asia, while cold extreme frequency increases over Scandinavia and Siberia (Figs. 9a,b). The anomalies are more pronounced in late winter (Fig. 9b), consistent with late winter stratospheretroposphere coupling induced by + IPV forcing (Fig. 8a). Including the warm Atlantic SST anomalies in the + AIV case leads to a striking difference in the response of cold extremes over Eurasia and North America (Figs. 9c,d). The increase in cold extremes over Scandinavia/Siberia is almost entirely canceled out, and the decrease in cold extremes over western North America is also reduced, especially in late winter. This is a consequence of reduced stratosphere-troposphere coupling with + AMV 

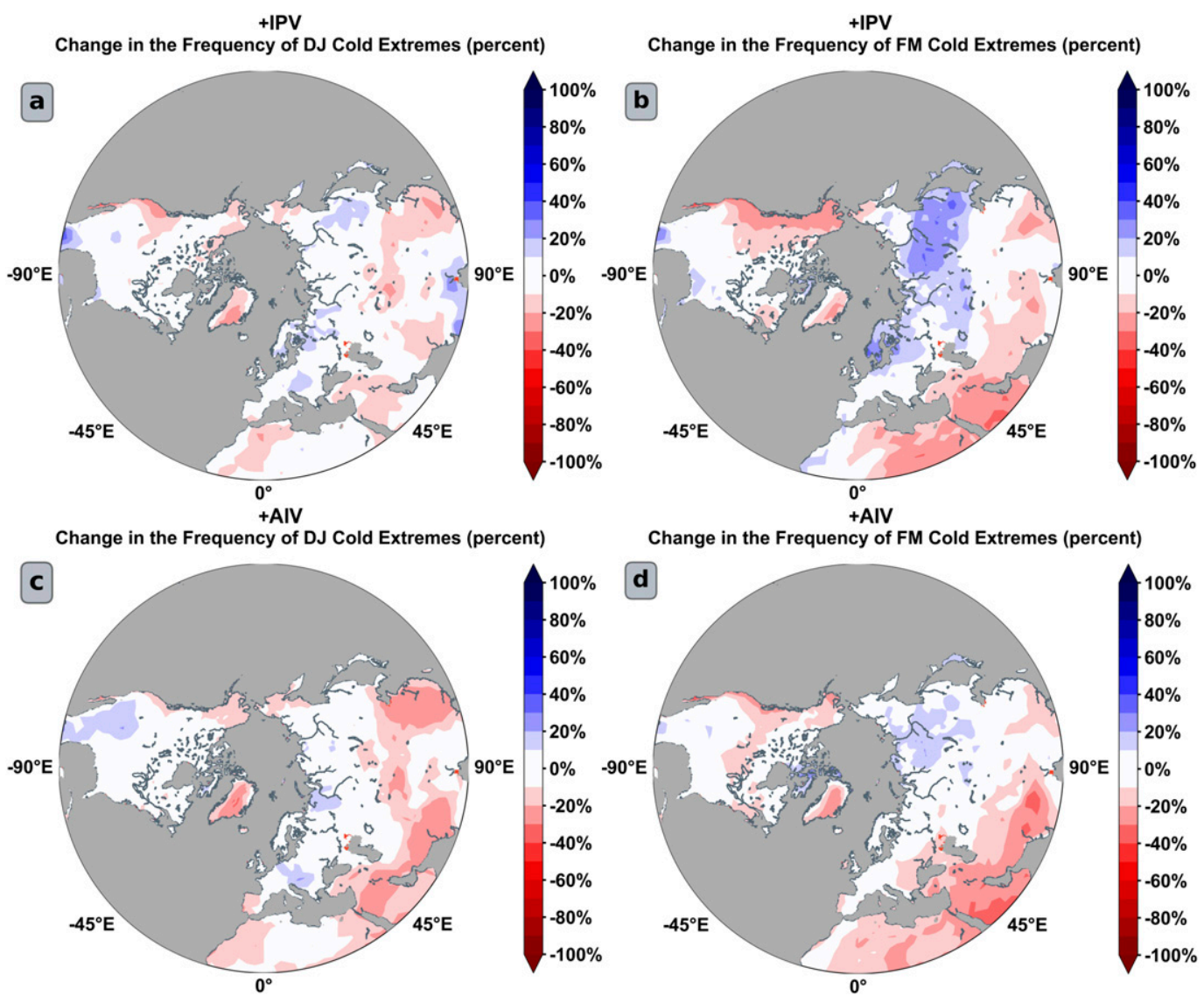

Change in the Frequency of FM Cold Extremes (percent)

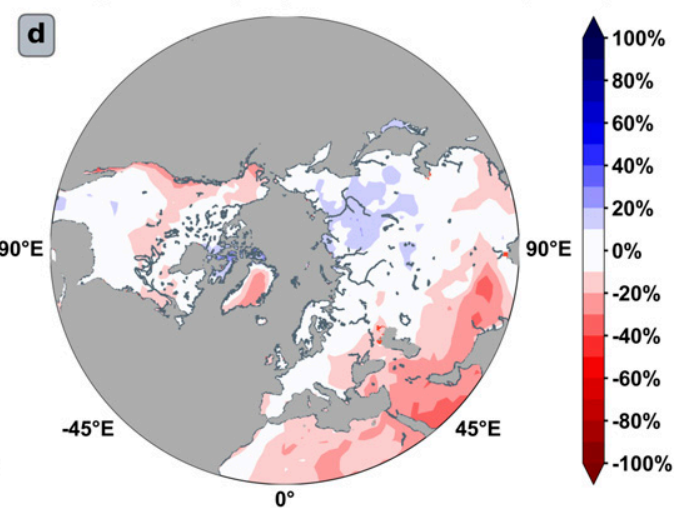

FIG. 9. The change in frequency of cold extremes for +IPV in (a) early and (b) late winter. (c),(d) As in (a) and (b), but for + AIV. Increases in frequency are shaded in blue and decreases in red. Cold extremes are days during which the daily temperature falls below the 10th percentile temperature value for that specific day and location.

identified in Fig. 8, and a clear illustration of how interbasin connections have to be considered when trying to predict decadal variability in extreme temperatures.

\section{e. Results from similar simulations with ARPEGE-Climat}

To continue exploring the link between the +AMV and the weakened Aleutian low, we analyze the ARPEGE-Climat atmospheric responses to the same perturbation experiments. The extended winter $500-\mathrm{hPa}$ streamfunction anomalies produced by ARPEGE-Climat (Fig. 10) compare well with same anomalies in WACCM (Fig. 2) over the Pacific. A strong + PNA pattern and deepening of the Aleutian low manifest in response to + IPV forcing (Fig. 10a). Anticyclonic anomalies span the entire North Pacific when forced by the +AMV (Fig. 10b). The deepening of the Aleutian low is reduced in the +AIV case compared to the +IPV alone (Fig. 10c). These observations of the streamfunction anomalies in the Pacific are consistent at the surface and at $200 \mathrm{hPa}$ (not shown). Note that the attenuation of the Aleutian low is more conspicuous in late winter (Fig. S2) and also that the atmospheric responses in ARPEGE-Climat are generally slightly weaker than in WACCM.

Figure 11 shows the correlations and RMSEs calculated between the +IPV and + AMV ARPEGE-Climat 500-hPa streamfunction responses and the same field for +AIV. They are very similar to those generated while using WACCM (Fig. 3), with the +AMV response being anticorrelated with the spatial pattern of anomalies in the North Pacific (Fig. 11b). ARPEGEClimat also exhibits an increase in upward wave activity in the North Pacific under + IPV (Fig. S3b), which is reduced by + AMV (Figs. S3c,d). Therefore, the ARPEGEClimat results are consistent with the WACCM results over the Pacific basin and support our claim that the atmospheric response to + AMV forcing destructively interferes with the deepening of the Aleutian low during boreal winter.

However, the ARPEGE-Climat experiments also exhibit striking differences. First, no significant stratospheric jet response is found in any of the simulations, 


\section{ARPEGE DJFM $500 \mathrm{hPa}$ Streamfunction Anomalies $\left(10^{6} \mathrm{~m}^{2} \mathrm{~s}^{-1}\right)$}

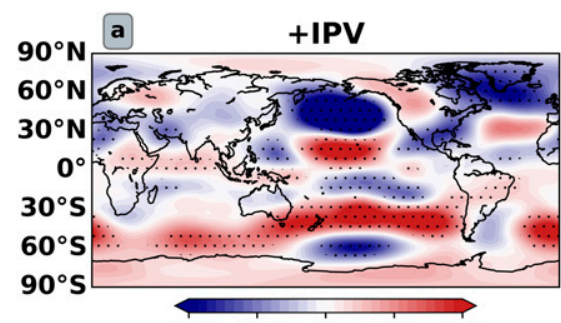

$\begin{array}{lllll}-1.0 & -0.5 & 0 & 0.5 & 1.0\end{array}$
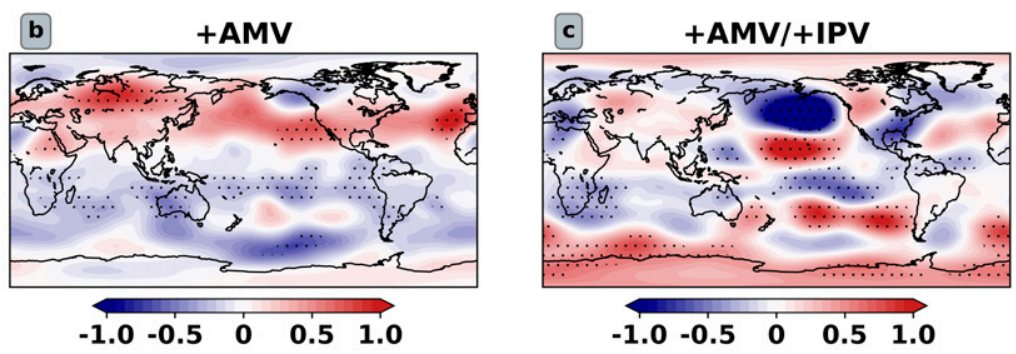

ARPEGE DJFM Sea Level Pressure Anomalies (hPa)

d

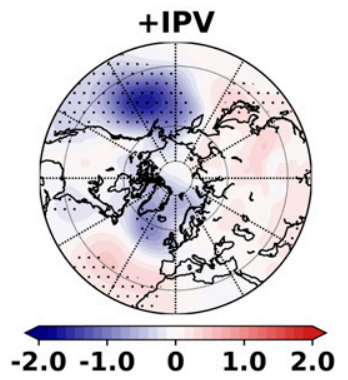

e

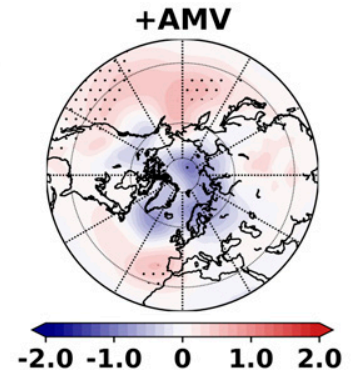

f

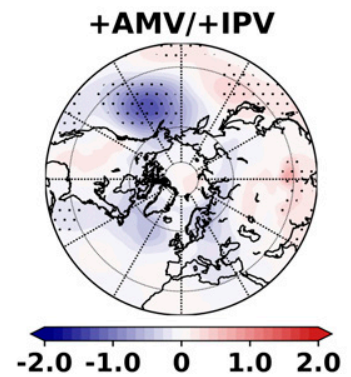

FIG. 10. As in Fig. 2, but for ARPEGE-Climat rather than WACCM.

despite increased upward wave activity flux in the North Pacific and convergence of the EP flux in the stratosphere (Figs. 12a,b,e,f). This intermodel contrast may be linked to the ability of the wave- 1 planetary wave to propagate vertically into the high-latitude stratosphere. At $100 \mathrm{hPa}$, WACMM's + IPV wave-1 response (Fig. S4a) is roughly double the magnitude of the wave-1 response simulated by ARPEGE-Climat (Fig. S4b) over the polar cap. With reduced upward propagation of wave 1 past $100 \mathrm{hPa}$ and subsequently less wave breaking, there is reduced forcing on the stratospheric westerlies in ARPEGE-Climat. This difference in the representation of wave 1 is also found when comparing the two AGCM climatologies. Figure S5 shows the climatological $100-\mathrm{hPa}$ wave-1 planetary waves simulated by WACCM and ARPEGE-Climat and observed in monthly data from the National Centers for Environmental Prediction (NCEP)-National Center for Atmospheric Research (NCAR) reanalysis (Kalnay et al. 1996). WACCM's wave-1 heights (Fig. S5b) exceed those observed in NCEP (Fig. S5a) while ARPEGEClimat's wave- 1 heights are closer to observations but underestimated (Fig. S5c). The tropospheric response to +IPV also differs in ARPEGE-Climat, as it resembles the positive phase of the NAO (Fig. 10a), versus a negative NAO in WACCM (Fig. 2a). This is consistent with the muted stratospheric response to planetary wave driving in ARPEGE-Climat (Figs. 12a,b), which results

\section{ARPEGE Spatial Correlation and RMSE of +AMV/+IPV with +AIV}

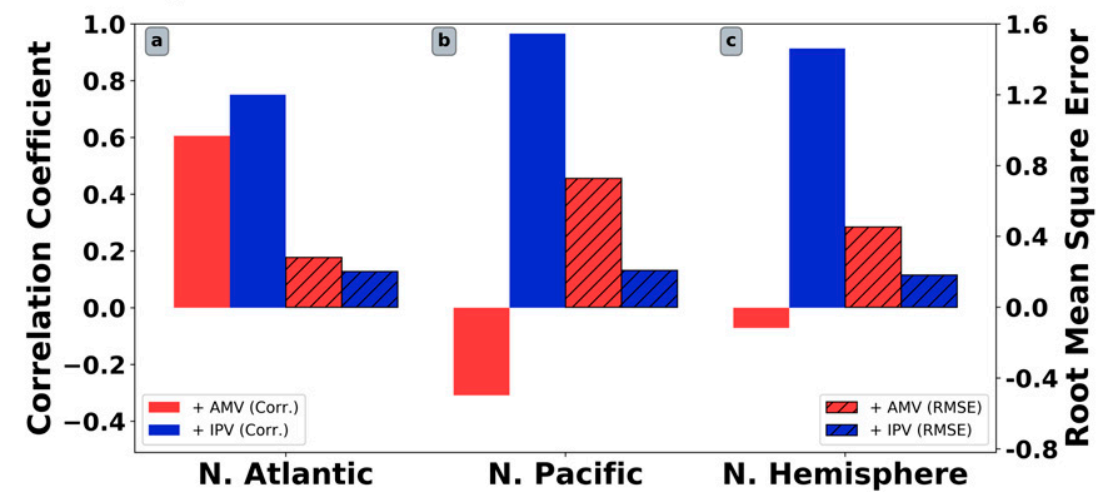

FIG. 11. As in Fig. 3, but for ARPEGE-Climat rather than WACCM. 


\section{ARPEGE Eliassen-Palm Flux}
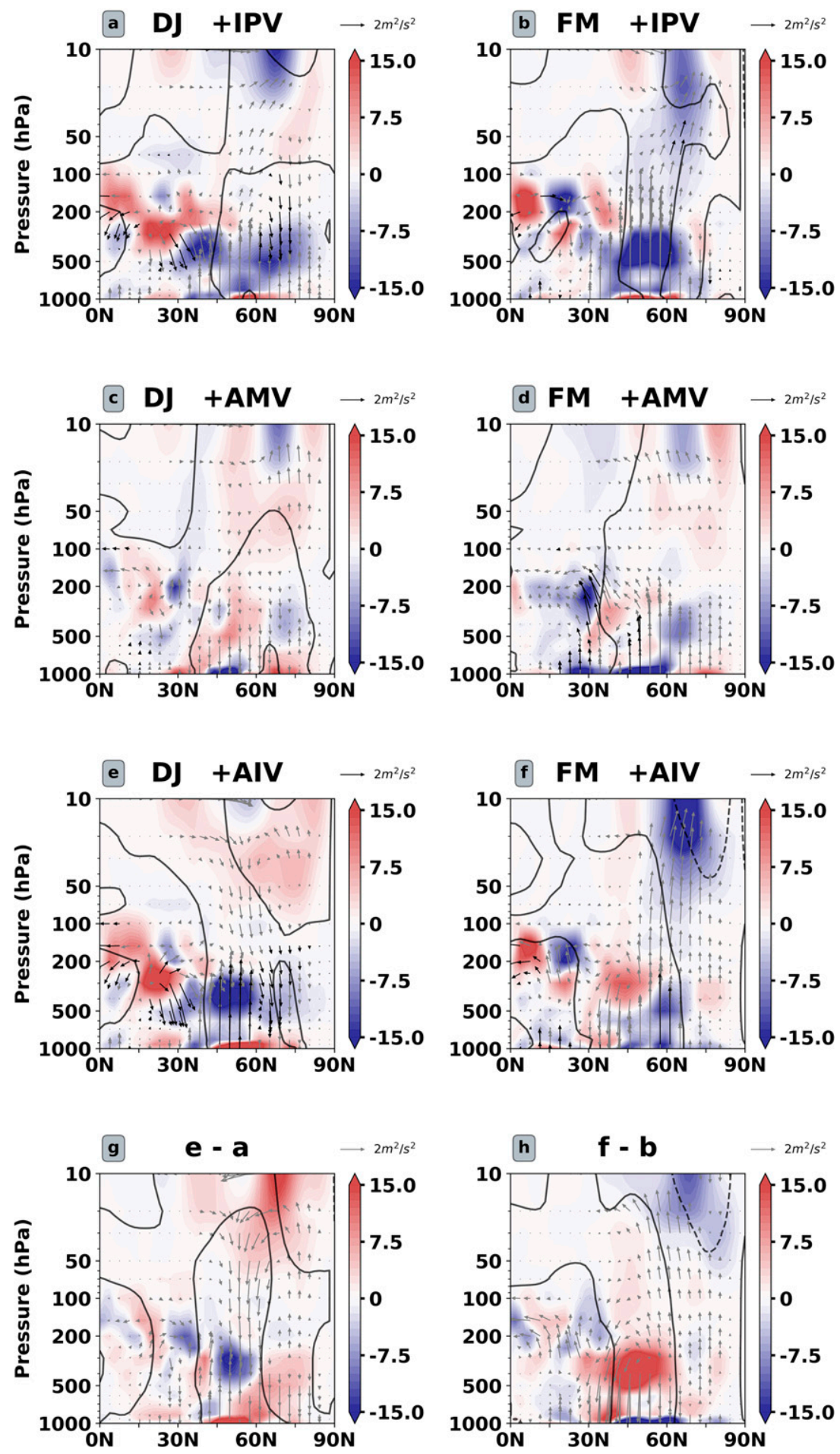

FIG. 12. As in Fig. 6, but for ARPEGE-Climat rather than WACCM. 


\section{ARPEGE DJFM Z200x Anomalies (m)}
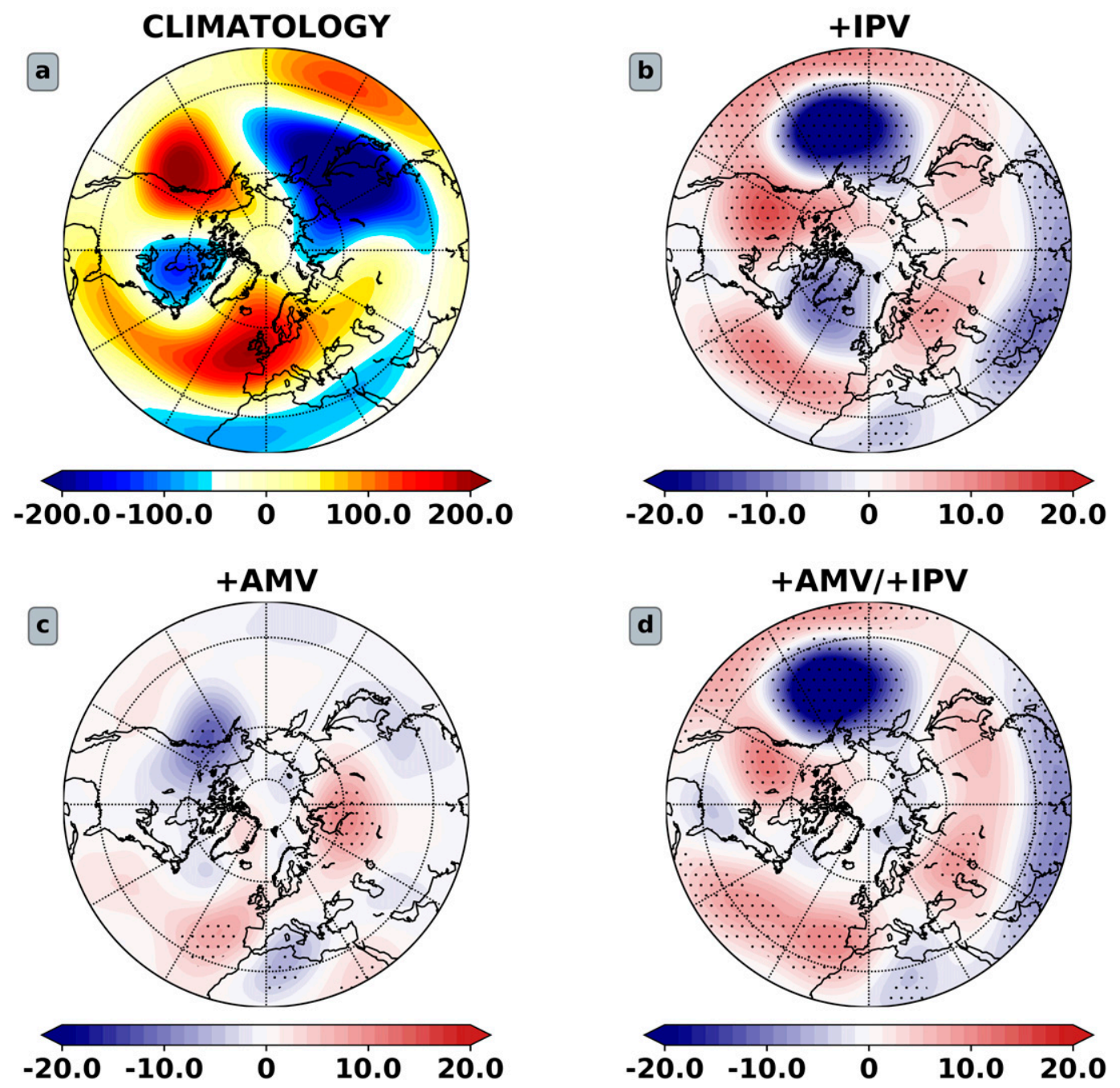

FIG. 13. As in Fig. 5, but for ARPEGE-Climat rather than WACCM.

in a stronger stratospheric jet that promotes positive NAM/NAO anomalies in the troposphere.

Second, under + AMV, ARPEGE-Climat does not feature the $200-\mathrm{hPa}$ wave train propagating from the tropical western Pacific into the North Pacific, that we identify as a cause for weaker Aleutian low response in + AIV (Fig. 13c). Furthermore, the reduced downward propagation of the NAM in late winter is apparent in WACCM, but not in ARPEGE-Climat (Figs. S2e,f). This means that the modulation of the North Pacific + IPV response by + AMV originates from a different mechanism than the two we have identified in WACCM: 1) suppressed upper tropospheric divergence in the tropical western Pacific and the associated 200-hPa Rossby wave train and 2) reduced downward propagation of the stratospheric response. An alternative mechanism, consistent with Sun et al. (2017), is that + AMV forces upper tropospheric divergence in the Atlantic, which is directly compensated for by upper tropospheric convergence in the North Pacific, subsidence, and an attenuated Aleutian low, without involving a significant perturbation of the Walker circulation. Such a mechanism will have to be investigated in future work.

\section{Discussion and conclusions}

In this study, we use idealized global atmospheric simulations with WACCM and ARPEGE-Climat to investigate the boreal winter atmospheric response to + IPV, + AMV, and + AIV SST forcings. A robust 
feature of the atmospheric response to + IPV and + AIV forcing is the positive PNA wave train leading to a deepening of the Aleutian low, consistent with previous studies (García-Herrera et al. 2006; Cagnazzo and Manzini 2009; Kren et al. 2016; Hu et al. 2017; Kang and Tziperman 2017; Yang et al. 2017; Polvani et al. 2017). The + AMV opposes the North Pacific atmospheric response to + IPV forcing and leads to a weaker response of the Aleutian low in +AIV. In WACCM, we have identified two different mechanisms to explain this cancellation effect: 1) a modulation of the Walker circulation that induces upper tropospheric convergence in the western Pacific, reducing upper-level divergence and the associated tropics-extratropics Rossby wave train that normally deepens the Aleutian low, and 2) reduced downward propagation of stratospheric anomalies into the troposphere, preventing reinforcement of the deepened Aleutian low. In ARPEGE-Climat, the cancellation effect of the +AMV is present, although these two mechanisms are absent. This suggests that an additional mechanism exists, which may be a simple compensation of upper-level divergence in the North Atlantic by upper-level convergence in the North Pacific and subsidence through the Aleutian low.

In WACCM, + IPV and + AIV both induce a warmer polar stratosphere, despite reduced upward wave activity flux in the North Pacific with the inclusion of + AMV. Indeed, additional upward wave activity flux over Siberia under + AIV compensates for the reduced upward wave activity flux in the North Pacific. Consistent with this result, the numbers of SSWs under + AIV (179) and +IPV (176) are nearly the same. Despite the + AMV not dramatically changing the stratospheric response to +IPV, it appears to exert a significant influence on the degree of strotosphere-troposphere coupling. Cold extreme temperatures become more frequent over Eurasia in response to the +IPV during late winter, consistent with increased stratospherictropospheric coupling and the negative NAM response. Including the + AMV reduces this coupling and the increase in cold extremes vanishes, which substantiates the importance of considering interbasin connections and their influence on stratosphere-troposphere coupling when investigating changes in mean climate and extreme events.

Observations are too short to investigate the role of multidecadal modes of variability on the climate with great confidence. This is especially true in the stratosphere where radiosonde measurements only began in the 1950s. However, in the troposphere, the recent availability of twentieth-century reanalyses allows us to discuss our modeling results and put them in perspective with the real world. Composites of extended winter
TABLE 3. The +IPV, +AMV, and + AIV years from the IPV indices of Henley et al. (2015) and the AMV indices of Trenberth and Shea (2006) and Trenberth et al. (2017).

\begin{tabular}{ll}
\hline \hline Forcing field & \multicolumn{1}{c}{ Years } \\
\hline + IPV & 1926-33, 1938-45, 1977-99, 2015-17 (42 total years) \\
+ AMV & 1924-64, 1998-2017 (41 total years) \\
+ AIV & 1926-33, 1938-45, 1998-99, 2015-17 (21 total years) \\
\hline
\end{tabular}

Northern Hemisphere sea level pressure (SLP) anomalies and 200-hPa stationary wave anomalies are made using ERA-20C reanalysis data (Poli et al. 2016) provided by the European Centre for Medium-Range Weather Forecasts (Fig. S6). Positive IPV and AMV years (Table 3) consistent with Henley et al. (2015) and Trenberth and Shea (2006) are selected to create composites based on the 1926-2010 climatology (we discard earlier data due to sparsity of observations at this time).

The corresponding SST anomalies (from HadISST; Rayner et al. 2003) are also shown. Note that each dataset is detrended to remove the global warming trend. As expected, the Aleutian low deepens with + IPV, a response consistent at the surface (Fig. S6f) and at $200 \mathrm{hPa}$ (Fig. S6e). However, + AMV opposes the response to +IPV in the North Pacific at the surface (Fig. S6i) and at $200 \mathrm{hPa}$ (Fig. S6h). Furthermore, at $200 \mathrm{hPa}$, a stationary wave propagates out of the central Pacific into the North Pacific where it increases the local height field (Fig. S6h). These SLP and stationary wave results are also consistent with NCEP reanalysis data (not shown).

Of course, these reanalysis findings are limited by a short observational record of +IPV (42 years), + AMV (41 years), and + AIV (21 years; not shown). However, these results corroborate our key finding that the + AMV is coupled to the North Pacific via the Walker circulation and the associated tropics-extratropics Rossby wave train (cf. Fig. S6h and Fig. 5c). Unlike ERA-20C and NCEP (not shown), WACCM features the 200-hPa stationary wave propagating out of the tropical western Pacific, not the central Pacific. This discord may be attributable to the lack of ocean-atmosphere coupling in our AGCM simulations. Previous literature suggests that a surface low pressure manifests in the tropical western Pacific when the tropical Atlantic is warmer than average (McGregor et al. 2014; Chikamoto et al. 2016), the southern branch of which would oppose the climatological flow of the easterly trade winds. This may increase surface ocean stratification and SST anomalies north of the equator, and via the wind-evaporation-SST feedback, lead to a reorganization of the SST field and the associated upper tropospheric geopotential field, changing the origin of the wave train. 
This study is an attempt to evaluate the atmospheric response to + AMV and + IPV in a simplified AGCM framework, with constant SST forcing, and it will be interesting to compare our results with coupled oceanatmosphere simulations. Within the DCPP of CMIP6 (Boer et al. 2016), fully coupled ocean-atmosphere experiments that impose the observed + AMV and +IPV cycles will be carried out. We will then be able to verify whether the mechanisms identified in this study are retrieved in coupled ocean-atmosphere simulations. Further analyses should also document the response in terms of the North Atlantic and North Pacific storm tracks and eddymean flow interactions, a question we do not investigate in the present study. Moreover, the negative IPV and/or AMV experiments could also be explored to better assess the apparent nonlinearity of the atmospheric response.

Acknowledgments. We thank Cristophe Cassou for developing the SST fields for the DCPP described in Boer et al. (2016) that were used as forcing fields in this paper. We also thank the developers of the two AGCMs used. This research was supported by NSF Grant AGS1624038. We also acknowledge high-performance computing support from Yellowstone (ark:/85065/d7wd3xhc) provided by NCAR's CISL, sponsored by the NSF.

\section{REFERENCES}

Andrews, D. G., C. B. Leovy, and J. R. Holton, 1987: Middle Atmosphere Dynamics, International Geophysics Series, Vol. 40, Academic Press, 489 pp.

Baldwin, M. P., and T. J. Dunkerton, 1999: Propagation of the Arctic Oscillation from the stratosphere to the troposphere. J. Geophys. Res., 104, 30 937-30 946, https://doi.org/10.1029/ 1999JD900445.

- , and —, 2001: Stratospheric harbingers of anomalous weather regimes. Science, 294, 581-584, https://doi.org/10.1126/ science.1063315.

Boer, G. J., and Coauthors, 2016: The Decadal Climate Prediction Project (DCPP) contribution to CMIP6. Geosci. Model Dev., 9, 3751-3777, https://doi.org/10.5194/gmd-9-3751-2016.

Booth, B. B. B., N. J. Dunstone, P. R. Halloran, T. Andrews, and N. Bellouin, 2012: Aerosols implicated as a prime driver of twentieth-century North Atlantic climate variability. Nature, 484, 228-232, https://doi.org/10.1038/nature10946.

Butler, A. H., J. P. Sjoberg, D. J. Seidel, and K. H. Rosenlof, 2017: A sudden stratospheric warming compendium. Earth Syst. Sci. Data, 9, 63-76, https://doi.org/10.5194/essd-9-63-2017.

Cagnazzo, C., and E. Manzini, 2009: Impact of the stratosphere on the winter tropospheric teleconnections between ENSO and the North Atlantic and European region. J. Climate, 22, 12231238, https://doi.org/10.1175/2008JCLI2549.1.

Cane, M. A., A. C. Clement, L. N. Murphy, and K. Bellomo, 2017: Low-pass filtering, heat flux, and Atlantic multidecadal variability. J. Climate, 30, 7529-7553, https://doi.org/10.1175/ JCLI-D-16-0810.1.

Cassou, C., Y. Kushnir, E. Hawkins, A. Pirani, F. Kucharski, I. Kang, and N. Caltabiano, 2017: Decadal climate variability and predictability: Challenges and opportunities. Bull. Amer. Meteor. Soc., 99, 479-490, https://doi.org/10.1175/BAMS-D-16-0286.1.

Chafik, L., S. Häkkinen, M. H. England, J. A. Carton, S. Nigam, A. Ruiz-Barradas, A. Hannachi, and L. Miller, 2016: Global linkages originating from decadal oceanic variability in the subpolar North Atlantic. Geophys. Res. Lett., 43, 10909 10 919, https://doi.org/10.1002/2016GL071134.

Charlton, A. J., and L. M. Polvani, 2007: A new look at stratospheric sudden warmings. Part I: Climatology and modeling benchmarks. J. Climate, 20, 449-469, https://doi.org/10.1175/ JCLI3996.1.

Charlton-Perez, A. J., and L. M. Polvani, 2011: Corrigendum. J. Climate, 24, 5951-5951, https://doi.org/10.1175/JCLI-D-1100348.1.

Chen, P., and W. A. Robinson, 1992: Propagation of planetary waves between the troposphere and stratosphere. J. Atmos. Sci., 49, 2533-2545, https://doi.org/10.1175/1520-0469(1992)049<2533: POPWBT $>2.0 . \mathrm{CO} ; 2$.

Chikamoto, Y., T. Mochizuki, A. Timmermann, M. Kimoto, and M. Watanabe, 2016: Potential tropical Atlantic impacts on Pacific decadal climate trends. Geophys. Res. Lett., 43, 7143 7151, https://doi.org/10.1002/2016GL069544.

Christiansen, B., 2001: Downward propagation of zonal mean wind anomalies from the stratosphere to the troposphere: Model and reanalysis. J. Geophys. Res., 106, 27 307-27 322, https:// doi.org/10.1029/2000JD000214.

Clement, A., K. Bellomo, L. N. Murphy, M. A. Cane, T. Mauritsen, G. Radel, and B. Stevens, 2015: The Atlantic multidecadal oscillation without a role for ocean circulation. Science, $\mathbf{3 5 0}$, 320-324, https://doi.org/10.1126/science.aab3980.

Danabasoglu, G., and Coauthors, 2016: North Atlantic simulations in Coordinated Ocean-ice Reference Experiments phase II (CORE-II). Part II: Inter-annual to decadal variability. Ocean Modell., 97, 65-90, https://doi.org/10.1016/j.ocemod.2015.11.007.

Davini, P., J. Von Hardenberg, and S. Corti, 2015: Tropical origin for the impacts of the Atlantic multidecadal variability on the Euro-Atlantic climate. Environ. Res. Lett., 10, 094010, https:// doi.org/10.1088/1748-9326/10/9/094010.

Delworth, T., S. Manabe, and R. J. Stouffer, 1993: Interdecadal variations of the thermohaline circulation in a coupled oceanatmosphere model. J. Climate, 6, 1993-2011, https://doi.org/ 10.1175/1520-0442(1993)006<1993:IVOTTC > 2.0.CO;2.

—, F. Zeng, L. Zhang, R. Zhang, G. A. Vecchi, and X. Yang, 2017: The central role of ocean dynamics in connecting the North Atlantic Oscillation to the Atlantic multidecadal oscillation. J. Climate, 30, 3789-3805, https://doi.org/10.1175/ JCLI-D-16-0358.1.

Dong, B., and A. Dai, 2015: The influence of the interdecadal Pacific oscillation on temperature and precipitation over the globe. Climate Dyn., 45, 2667-2681, https://doi.org/10.1007/ s00382-015-2500-x.

Dunkerton, T., C. P. F. Hsu, and M. E. McIntyre, 1981: Some Eulerian and Lagrangian diagnostics for a model stratospheric warming. J. Atmos. Sci., 38, 819-844, https://doi.org/10.1175/ 1520-0469(1981)038<0819:SEALDF $>2.0 . C O ; 2$.

Edmon, H. J., Jr., B. J. Hoskins, and M. E. McIntyre, 1980: EliassenPalm cross sections for the troposphere. J. Atmos. Sci., 37, 2600-2616, https://doi.org/10.1175/1520-0469(1980)037<2600: EPCSFT $>2.0 . C O ; 2$.

Enfield, D. B., A. M. Mestas-Nuñez, and P. J. Trimble, 2001: The Atlantic Multidecadal Oscillation and its relation to rainfall and river flows in the continental US. Geophys. Res. Lett., 28 , 2077-2080, https://doi.org/10.1029/2000GL012745. 
England, M. H., and Coauthors, 2014: Recent intensification of wind-driven circulation in the Pacific and the ongoing warming hiatus. Nat. Climate Change, 4, 222, https://doi.org/10.1038/ nclimate 2106.

Fletcher, C. G., and P. J. Kushner, 2011: The role of linear interference in the annular mode response to tropical SST forcing. J. Climate, 24, 778-794, https://doi.org/10.1175/ 2010JCLI3735.1.

Frajka-Williams, E., C. Beaulieu, and A. Duchez, 2017: Emerging negative Atlantic Multidecadal Oscillation index in spite of warm subtropics. Sci. Rep., 7, 11224, https://doi.org/10.1038/ s41598-017-11046-x.

García-Herrera, R., N. Calvo, R. R. Garcia, and M. A. Giorgetta, 2006: Propagation of ENSO temperature signals into the middle atmosphere: A comparison of two general circulation models and ERA-40 reanalysis data. J. Geophys. Res., 111, D06101, https://doi.org/10.1029/2005jd006061.

García-Serrano, J., C. Cassou, H. Douville, A. Giannini, and F. J. Doblas-Reyes, 2017: Revisiting the ENSO teleconnection to the tropical North Atlantic. J. Climate, 30, 6945-6957, https:// doi.org/10.1175/JCLI-D-16-0641.1.

Giannini, A., J. C. H. Chiang, M. A. Cane, Y. Kushnir, and R. Seager, 2001: The ENSO teleconnection to the tropical Atlantic Ocean: Contributions of the remote and local SSTs to rainfall variability in the tropical Americas. J. Climate, 14, 4530-4544, https://doi.org/10.1175/1520-0442(2001)014<4530: TETTTT $>2.0 . \mathrm{CO} ; 2$.

Gray, S. T., L. J. Graumlich, J. L. Betancourt, and G. T. Pederson, 2004: A tree-ring based reconstruction of the Atlantic Multidecadal Oscillation since 1567 A.D. Geophys. Res. Lett., 31, L12205, https://doi.org/10.1029/2004GL019932.

Ham, Y. G., J. Y. Choi, and J. S. Kug, 2017: The weakening of the ENSO-Indian Ocean dipole (IOD) coupling strength in recent decades. Climate Dyn., 49, 249-261, https://doi.org/ 10.1007/s00382-016-3339-5.

Henley, B. J., J. Gergis, D. J. Karoly, S. B. Power, J. Kennedy, and C. K. Folland, 2015: A tripole index for the interdecadal Pacific oscillation. Climate Dyn., 45, 3077-3090, https://doi.org/ 10.1007/s00382-015-2525-1.

_ - and Coauthors, 2017: Spatial and temporal agreement in climate model simulations of the interdecadal Pacific oscillation. Environ. Res. Lett., 12, 044011, https://doi.org/10.1088/ 1748-9326/aa5cc8.

Horel, J. D., and J. M. Wallace, 1981: Planetary-scale atmospheric phenomena associated with the Southern Oscillation. Mon. Wea. Rev., 109, 813-829, https://doi.org/10.1175/ 1520-0493(1981)109<0813:PSAPAW > 2.0.CO;2.

Hu, J., T. Li, H. Xu, and S. Yang, 2017: Lessened response of boreal winter stratospheric polar vortex to El Niño in recent decades. Climate Dyn., 49, 263-278, https://doi.org/10.1007/ s00382-016-3340-z.

Huang, B., and Coauthors, 2015: Extended reconstructed sea surface temperature version 4 (ERSST. v4). Part I: Upgrades and intercomparisons. J. Climate, 28, 911-930, https://doi.org/ 10.1175/JCLI-D-14-00006.1.

Hurrell, J. W., and H. van Loon, 1997: Decadal variations in climate associated with the North Atlantic Oscillation. Climatic Change at High Elevation Sites, H. F. Diaz, M. Beniston, and R. S. Bradley, Eds., Springer, 69-94.

Jiang, P., Z. Yu, and M. R. Gautam, 2013: Pacific and Atlantic Ocean influence on the spatiotemporal variability of heavy precipitation in the western United States. Global Planet. Change, 109, 38-45, https://doi.org/10.1016/j.gloplacha.2013.07.004.
Joshi, M. K., and A. Rai, 2015: Combined interplay of the Atlantic multidecadal oscillation and the interdecadal Pacific oscillation on rainfall and its extremes over Indian subcontinent. Climate Dyn., 44, 3339-3359, https://doi.org/10.1007/s00382-014-2333-z.

Kalnay, E., and Coauthors, 1996: The NCEP/NCAR 40-Year Reanalysis Project. Bull. Amer. Meteor. Soc., 77, 437-471, https:// doi.org/10.1175/1520-0477(1996)077<0437:TNYRP>2.0.CO;2.

Kang, I.-S., H.-H. No, and F. Kucharski, 2014: ENSO amplitude modulation associated with the mean SST changes in the tropical central Pacific induced by Atlantic multidecadal oscillation. J. Climate, 27, 7911-7920, https://doi.org/10.1175/ JCLI-D-14-00018.1.

Kang, W., and E. Tziperman, 2017: More frequent sudden stratospheric warming events due to enhanced MJO forcing expected in a warmer climate. J. Climate, 30, 8727-8743, https:// doi.org/10.1175/JCLI-D-17-0044.1.

Karl, T. R., N. Nicholls, and A. Ghazi, 1999: CLIVAR/GCOS/ WMO workshop on indices and indicators for climate extremes workshop summary. Weather and Climate Extremes: Changes, Variations and a Perspective from the Insurance Industry, T. R. Karl, N. Nicholls, and A. Ghazi, Eds., Springer, 3-7, https://doi.org/10.1007/978-94-015-9265-9.

Kerr, R. A., 2000: A North Atlantic climate pacemaker for the centuries. Science, 288, 1984-1985, https://doi.org/10.1126/ science.288.5473.1984.

Kim, W. M., S. Yeager, P. Chang, and G. Danabasoglu, 2018: Lowfrequency North Atlantic climate variability in the Community Earth System Model Large Ensemble. J. Climate, 31, 787-813, https://doi.org/10.1175/JCLI-D-17-0193.1.

Knight, J. R., R. J. Allan, C. K. Folland, M. Vellinga, and M. E. Mann, 2005: A signature of persistent natural thermohaline circulation cycles in observed climate. Geophys. Res. Lett., 32, L20708, https://doi.org/10.1029/2005GL024233.

Knudsen, M. F., M.-S. Seidenkrantz, B. H. Jacobsen, and A. Kuijpers, 2011: Tracking the Atlantic Multidecadal Oscillation through the last 8,000 years. Nat. Commun., 2, 178, https://doi.org/10.1038/ncomms1186.

B. H. Jacobsen, M.-S. Seidenkrantz, and J. Olsen, 2014: Evidence for external forcing of the Atlantic Multidecadal Oscillation since termination of the Little Ice Age. Nat. Commun., 5, 3323, https://doi.org/10.1038/ncomms4323.

Kosaka, Y., and S.-P. Xie, 2013: Recent global-warming hiatus tied to equatorial Pacific surface cooling. Nature, 501, 403-407, https://doi.org/10.1038/nature12534.

Kren, A. C., D. R. Marsh, A. K. Smith, and P. Pilewskie, 2016: Wintertime Northern Hemisphere response in the stratosphere to the Pacific decadal oscillation using the Whole Atmosphere Community Climate Model. J. Climate, 29, 10311049, https://doi.org/10.1175/JCLI-D-15-0176.1.

Limpasuvan, V., D. W. Thompson, and D. L. Hartmann, 2004: The life cycle of the Northern Hemisphere sudden stratospheric warmings. J. Climate, 17, 2584-2596, https://doi.org/10.1175/ 1520-0442(2004)017<2584:TLCOTN>2.0.CO;2.

Lorenz, D. J., and D. L. Hartmann, 2003: Eddy-zonal flow feedback in the Northern Hemisphere winter. J. Climate, 16, 1212-1227, https://doi.org/10.1175/1520-0442(2003)16<1212: EFFITN $>2.0 . \mathrm{CO} ; 2$.

Lott, F., L. Guez, and P. Maury, 2012: A stochastic parameterization of non-orographic gravity waves: Formalism and impact on the equatorial stratosphere. Geophys. Res. Lett., 39, L06807, https://doi.org/10.1029/2012GL051001.

Lubis, S. W., K. Matthes, N.-E. Omrani, N. Harnik, and S. Wahl, 2016: Influence of the quasi-biennial oscillation and sea 
surface temperature variability on downward wave coupling in the Northern Hemisphere. J. Atmos. Sci., 73, 1943-1965, https:// doi.org/10.1175/JAS-D-15-0072.1.

Mantua, N. J., S. R. Hare, Y. Zhang, J. M. Wallace, and R. Francis, 1997: A Pacific interdecadal climate oscillation with impacts on salmon production. Bull. Amer. Meteor. Soc., 78, 1069-1079, https://doi.org/10.1175/1520-0477(1997)078<1069: APICOW $>2.0 . \mathrm{CO} ; 2$.

Marsh, D. R., M. J. Mills, D. E. Kinnison, J.-F. Lamarque, N. Calvo, and L. M. Polvani, 2013: Climate change from 1850 to 2005 simulated in CESM1(WACCM). J. Climate, 26, 73727391, https://doi.org/10.1175/JCLI-D-12-00558.1.

Martius, O., L. M. Polvani, and H. C. Davies, 2009: Blocking precursors to stratospheric sudden warming events. Geophys. Res. Lett., 36, L14806, https://doi.org/10.1029/2009GL038776.

McGregor, S., A. Timmermann, M. F. Stuecker, M. H. England, M. Merrifield, F.-F. Jin, and Y. Chikamoto, 2014: Recent Walker circulation strengthening and Pacific cooling amplified by Atlantic warming. Nat. Climate Change, 4, 888-892, https:// doi.org/10.1038/nclimate2330.

McIntyre, M. E., 1982: How well do we understand the dynamics of stratospheric warmings? J. Meteor. Soc. Japan, 60, 37-65, https://doi.org/10.2151/jmsj1965.60.1_37.

Meehl, G. A., A. Hu, J. M. Arblaster, J. Fasullo, and K. E. Trenberth, 2013: Externally forced and internally generated decadal climate variability associated with the interdecadal Pacific oscillation. J. Climate, 26, 7298-7310, https://doi.org/ 10.1175/JCLI-D-12-00548.1.

—_ _ _ , and H. Teng, 2016: Initialized decadal prediction for transition to positive phase of the interdecadal Pacific oscillation. Nat. Commun., 7, 11718, https://doi.org/10.1038/ ncomms11718.

Newman, M., and Coauthors, 2016: The Pacific decadal oscillation, revisited. J. Climate, 29, 4399-4427, https://doi.org/10.1175/ JCLI-D-15-0508.1.

Nishii, K., H. Nakamura, and Y. J. Orsolini, 2010: Cooling of the wintertime Arctic stratosphere induced by the western Pacific teleconnection pattern. Geophys. Res. Lett., 37, L13805, https://doi.org/10.1029/2010GL043551.

Omrani, N.-E., N. S. Keenlyside, J. Bader, and E. Manzini, 2014: Stratosphere key for wintertime atmospheric response to warm Atlantic decadal conditions. Climate Dyn., 42, 649-663, https://doi.org/10.1007/s00382-013-1860-3.

O'Reilly, C. H., M. Huber, T. Woollings, and L. Zanna, 2016: The signature of low-frequency oceanic forcing in the Atlantic multidecadal oscillation. Geophys. Res. Lett., 43, 2810-2818, https://doi.org/10.1002/2016GL067925.

Otterå, O. H., M. Bentsen, H. Drange, and L. L. Suo, 2010: External forcing as a metronome for Atlantic multidecadal variability. Nat. Geosci., 3, 688-694, https://doi.org/10.1038/ ngeo955.

Peings, Y., and G. Magnusdottir, 2014: Forcing of the wintertime atmospheric circulation by the multidecadal fluctuations of the North Atlantic Ocean. Environ. Res. Lett., 9, 034018, https:// doi.org/10.1088/1748-9326/9/3/034018.

— , and — 2016: Wintertime atmospheric response to Atlantic multidecadal variability: Dependence on stratospheric representation and ocean-atmosphere coupling. Climate Dyn., 47, 1029-1047, https://doi.org/10.1007/s00382-015-2887-4.

Plumb, R. A., 1981: Instability of the distorted polar night vortex: A theory of stratospheric warmings. J. Atmos. Sci., 38, 2514-2531, https://doi.org/10.1175/1520-0469(1981)038<2514: IOTDPN $>2.0 . \mathrm{CO} ; 2$.
- 1985: On the three-dimensional propagation of stationary waves. J. Atmos. Sci., 42, 217-229, https://doi.org/10.1175/ 1520-0469(1985)042<0217:OTTDPO > 2.0.CO;2.

- 2004: Atmospheric and Ocean Circulations.MIT OpenCourseWare, Massachusetts Institute of Technology, https://ocw.mit.edu/courses/earth-atmospheric-and-planetarysciences/12-333-atmospheric-and-ocean-circulations-spring-2004/ (License: Creative Commons BY-NC-SA).

Poli, P., and Coauthors, 2016: ERA-20C: An atmospheric reanalysis of the twentieth century. J. Climate, 29, 4083-4097, https://doi.org/10.1175/JCLI-D-15-0556.1.

Polvani, L. M., L. Sun, A. H. Butler, J. H. Richter, and C. Deser 2017: Distinguishing stratospheric sudden warmings from ENSO as key drivers of wintertime climate variability over the North Atlantic and Eurasia. J. Climate, 30, 1959-1969, https:// doi.org/10.1175/JCLI-D-16-0277.1.

Rayner, N. A., D. E. Parker, E. B. Horton, C. K. Folland, L. V. Alexander, D. P. Rowell, E. C. Kent, and A. Kaplan, 2003 Global analyses of sea surface temperature, sea ice, and night marine air temperature since the late nineteenth century. J. Geophys. Res., 108, 4407, https://doi.org/10.1029/2002JD002670.

Sardeshmukh, P. D., and B. J. Hoskins, 1988: The generation of global rotational flow by steady idealized tropical divergence. J. Atmos. Sci., 45, 1228-1251, https://doi.org/10.1175/15200469(1988)045<1228:TGOGRF>2.0.CO;2.

Scaife, A. A., and Coauthors, 2017: Tropical rainfall, Rossby waves and regional winter climate predictions. Quart. J. Roy. Meteor. Soc., 143, 1-11, https://doi.org/10.1002/qj.2910.

Simpkins, G. R., Y. Peings, and G. Magnusdottir, 2016: Pacific influences on tropical Atlantic teleconnections to the Southern Hemisphere high latitudes. J. Climate, 29, 6425-6444, https://doi.org/10.1175/JCLI-D-15-0645.1.

Smith, K., R. Neely, D. Marsh, and L. Polvani, 2014: The Specified Chemistry Whole Atmosphere Community Climate Model (SC-WACCM). J. Adv. Model. Earth Syst., 6, 883-901, https:// doi.org/10.1002/2014MS000346.

Steinman, B. A., M. E. Mann, and S. K. Miller, 2015: Atlantic and Pacific multidecadal oscillations and Northern Hemisphere temperatures. Science, 347, 988-991, https://doi.org/10.1126/ science. 1257856

Sun, C., F. Kucharski, J. Li, F. Jin, I. Kang, and R. Ding, 2017: Western tropical Pacific multidecadal variability forced by the Atlantic multidecadal oscillation. Nat. Commun., 8, 15998, https://doi.org/10.1038/ncomms15998.

Sutton, R. T., and D. L. R. Hodson, 2005: Atlantic Ocean forcing of North American and European summer climate. Science, 309, 115-118, https://doi.org/10.1126/science.1109496.

Taguchi, M., and D. L. Hartmann, 2006: Increased occurrence of stratospheric sudden warmings during El Niño as simulated by WACCM. J. Climate, 19, 324-332, https://doi.org/10.1175/ JCLI3655.1.

Tandon, N. F., and P. J. Kushner, 2015: Does external forcing interfere with the AMOC's influence on North Atlantic sea surface temperature? J. Climate, 28, 6309-6323, https:// doi.org/10.1175/JCLI-D-14-00664.1.

Terray, L., 2012: Evidence for multiple drivers of North Atlantic multi-decadal climate variability. Geophys. Res. Lett., 39, L19712, https://doi.org/10.1029/2012GL053046.

Ting, M., Y. Kushnir, R. Seager, and C. H. Li, 2009: Forced and internal twentieth-century SST trends in the North Atlantic. J. Climate, 22, 1469-1481, https://doi.org/10.1175/2008JCLI2561.1.

Tokinaga, H., S.-P. Xie, and H. Mukougawa, 2017: Early 20thcentury Arctic warming intensified by Pacific and Atlantic 
multidecadal variability. Proc. Natl. Acad. Sci. USA, 114, 6227-6232, https://doi.org/10.1073/pnas.1615880114.

Trenberth, K. E., and D. J. Shea, 2006: Atlantic hurricanes and natural variability in 2005. Geophys. Res. Lett., 33, L12704, https://doi.org/10.1029/2006GL026894.

and Coauthors, Eds., 2017: The Climate Data Guide: Atlantic Multi-decadal Oscillation (AMO). NCAR, accessed 11 June 2018, https://climatedataguide.ucar.edu/climate-data/atlanticmulti-decadal-oscillation-amo.

Vimont, D. J., and J. P. Kossin, 2007: The Atlantic meridional mode and hurricane activity. Geophys. Res. Lett., 34, L07709, https://doi.org/10.1029/2007GL029683.

Voldoire, A., and Coauthors, 2013: The CNRM-CM5. 1 global climate model: Description and basic evaluation. Climate Dyn., 40, 2091-2121, https://doi.org/10.1007/s00382-0111259-y.

_ , and Coauthors, 2019: Evaluation of CMIP6 DECK experiments with CNRM-CM6-1. J. Adv. Model. Earth Syst., https:// doi.org/10.1029/2019MS001683, in press.

Wallace, J. M., and D. S. Gutzler, 1981: Teleconnections in the geopotential height field during the Northern Hemisphere winter. Mon. Wea. Rev., 109, 784-812, https://doi.org/10.1175/ 1520-0493(1981)109<0784:TITGHF $>2.0$. CO;2.

Wang, C., 2004: ENSO, Atlantic climate variability, and the Walker and Hadley circulations. The Hadley Circulation: Past,
Present, and Future, H. F. Diaz and R. S. Bradley, Eds., Kluwer Academic, 173-202.

—, S. Dong, A. T. Evan, G. R. Foltz, and S.-K. Lee, 2012: Multidecadal covariability of North Atlantic sea surface temperature, African dust, Sahel rainfall, and Atlantic hurricanes. J. Climate, 25, 5404-5415, https://doi.org/10.1175/JCLI-D-11-00413.1.

Watson, P. A., A. Weisheimer, J. R. Knight, and T. N. Palmer, 2016: The role of the tropical west Pacific in the extreme Northern Hemisphere winter of 2013/2014. J. Geophys. Res., 121, 1698-1714, https://doi.org/10.1002/2015jd024048.

White, R. H., D. S. Battisti, and A. Sheshadri, 2018: Orography and the boreal winter stratosphere: The importance of the Mongolian mountains. Geophys. Res. Lett., 45, 2088-2096, https:// doi.org/10.1002/2018GL077098.

Woo, S.-H., M.-K. Sung, S.-W. Son, and J.-S. Kug, 2015: Connection between weak stratospheric vortex events and the Pacific decadal oscillation. Climate Dyn., 45, 3481-3492, https://doi.org/ 10.1007/s00382-015-2551-z.

Yang, S., T. Li, J. Hu, and X. Shen, 2017: Decadal variation of the impact of La Niña on the winter Arctic stratosphere. Adv. Atmos. Sci., 34, 679-684, https://doi.org/10.1007/s00376-016-6184-x.

Zhang, L., and C. Wang, 2013: Multidecadal North Atlantic sea surface temperature and Atlantic meridional overturning circulation variability in CMIP5 historical simulations. J. Geophys. Res. Oceans., 118, 5772-5791, https://doi.org/10.1002/jgrc.20390. 


\title{
CORRIGENDUM
}

\author{
Dillon Elsbury, ${ }^{\mathrm{a}}$ Yannick Peings, ${ }^{\mathrm{a}}$ David Saint-Martin, ${ }^{\mathrm{b}}$ Hervé Douville, ${ }^{\mathrm{b}}$ AND \\ GUDRUN MAGNUSDOTTIR ${ }^{\mathrm{a}}$ \\ ${ }^{a}$ Department of Earth System Science, University of California, Irvine, Irvine, California \\ ${ }^{\mathrm{b}}$ CNRM-GMGEC, Météo-France, Toulouse, France
}

(Manuscript received 17 May 2021, in final form 13 July 2021)

In Table 2 of Elsbury et al. (2019), titled "The atmospheric response to positive IPV, positive AMV, and their combination in boreal winter," the number and frequency of sudden stratospheric warmings (SSWs) for various background interdecadal Pacific variability (IPV) and Atlantic multidecadal variability (AMV) states are incorrect. The reproduction of the Charlton and Polvani $(2007,2011)$ SSW algorithm used includes final warmings, which increases the SSW occurrences. Following correction, the number of SSWs decreases across all simulations. These results are printed in Table 2 below. The climatological frequency is 0.52 events per season in our control, lower than the frequency detected in reanalysis, but consistent with the frequency retrieved by Marsh et al. (2013), who also use WACCM4. With the correction, the percent increase in SSWs relative to control remains very similar, equaling $15 \%$ for + AMV, $26 \%$ for + IPV, and $33 \%$ for + AIV ( + AMV and + IPV together). These figures appear correctly in the table. In general, these errors do not change any of the major findings of the manuscript. We apologize for the confusion the suspiciously high SSW results may have caused.

TABLE 2. Number and frequency of stratospheric sudden warmings in events per extended winter season. Both number of events and frequency are calculated using daily data (November-March) over the entire 200-yr period.

\begin{tabular}{ccc}
\hline \hline Forcing field & Number of SSWs & Events per season \\
\hline Control & 103 & 0.52 \\
+ IPV & 130 & 0.65 \\
+ AMV & 118 & 0.59 \\
+ AIV & 137 & 0.69 \\
\hline
\end{tabular}

\section{REFERENCES}

Charlton, A. J., and L. M. Polvani, 2007: A new look at stratospheric sudden warmings. Part I: Climatology and modeling benchmarks. J. Climate, 20, 449-469, https://doi.org/10.1175/JCLI3996.1.

—, and —, 2011: Corrigendum. J. Climate, 24, 5951, https://doi.org/10.1175/JCLI-D-11-00348.1.

Elsbury, D., Y. Peings, D. Saint-Martin, H. Douville, and G. Magnusdottir, 2019: The atmospheric response to positive IPV, positive AMV, and their combination in boreal winter. J. Climate, 32, 4193-4213, https:// doi.org/10.1175/JCLI-D-18-0422.1.

Marsh, D. R., M. J. Mills, D. E. Kinnison, J.-F. Lamarque, N. Calvo, and L. M. Polvani, 2013: Climate change from 1850 to 2005 simulated in CESM1(WACCM). J. Climate, 26, 7372-7391, https://doi.org/10.1175/ JCLI-D-12-00558.1. 